Portland State University

PDXScholar

Fall 11-14-2014

\title{
Modulation of the Cardiac Calcium Release Channel by Homocysteine Thiolactone
}

Laura Jean Owen

Portland State University

Follow this and additional works at: https://pdxscholar.library.pdx.edu/open_access_etds

Part of the Physics Commons

Let us know how access to this document benefits you.

\section{Recommended Citation}

Owen, Laura Jean, "Modulation of the Cardiac Calcium Release Channel by Homocysteine Thiolactone" (2014). Dissertations and Theses. Paper 2071.

https://doi.org/10.15760/etd.2070

This Dissertation is brought to you for free and open access. It has been accepted for inclusion in Dissertations and Theses by an authorized administrator of PDXScholar. Please contact us if we can make this document more accessible: pdxscholar@pdx.edu. 
Modulation of the Cardiac Calcium Release Channel by Homocysteine

Thiolactone

\author{
by \\ Laura Jean Owen
}

A dissertation submitted in partial fulfillment of the requirements for the degree of

\author{
Doctor of Philosophy \\ in \\ Applied Physics
}

\author{
Dissertation Committee: \\ Jonathan Abramson, Chair \\ Drake Mitchell \\ Jeffrey Singer \\ Robert Strongin
}

\author{
Portland State University \\ 2014
}


(C) 2014 Laura Jean Owen 


\begin{abstract}
Elevated levels in blood serum $(>10 \mu \mathrm{mol} / \mathrm{L})$ of the amino acid homocysteine is strongly correlated with the incidence of heart failure (HF). We present evidence that the cyclic thioester, homocysteine thiolactone $(\mathrm{HTL})$, a metabolic product of homocysteine, irreversibly modifies proteins that regulate the contractile process in cardiac muscle. Two proteins found in the sarcoplasmic reticulum (SR), the $\mathrm{Ca}^{2+}$ pump (SERCA2), and the ryanodine receptor (RyR2), are responsible for controlling the cytosolic $\mathrm{Ca}^{2+}$ concentration and hence the contractile state of the heart. While both improper $\mathrm{Ca}^{2+}$ handling and elevated homocysteine levels have been considered bio-markers in HF, a direct connection between the two has not previously been made. We show that HTL reacts with lysine residues on RyR2, generating a $\mathrm{N} \varepsilon$-homocysteine-protein, which results in carbonyl formation and a change in the $\mathrm{Ca}^{2+}$ sensitivity of RyR2. This is a new molecular mechanism linking elevated levels of Homocysteine, improper $\mathrm{Ca}^{2+}$ handling and heart failure. This work was supported by NIH 1 R41 HL105063-01 to J. Abramson and R. Strongin.
\end{abstract}


Dedication

To my parents, Phil \& Sue Owen

Without your love, advice, support, and donations to the LLF (Little Laura Fund) I would not have been able to accomplish my dream. 


\section{Acknowledgements}

I am sincerely grateful to my advisor, Dr Jon Abramson, for his continuous support, patience, and motivation. I could not have imagined having a better advisor and mentor. Many thanks to my fellow graduate students of the Abramson Lab; Tom Dornan, Yanping Ye, Allison Lawrence and Robert Klipp. Thank you, for everything. Thank you also to Dr. Jeff Singer and the Singer lab; Mark West, Brittney Davidge, and Jennifer Mitchell. I greatly appreciate the countless conversations and western blotting advice. Thank you to Dr Strongin and the Strongin Lab; Dr. Martha Sibrian-Vazquez, Dr. Jorge Escobedo, Jialu Wang, \& Shelly Chu for introducing me to the wondrous HTL molecule \& answering all manner of chemistry questions. Thanks also to Dr Drake Mitchell for teaching the best class I took at Portland State and for serving on my committee. Thank you to my good friend Dr. Marilyn Mackiewicz for all her help and fabulous advice. Thank you to Mike Dandy for keeping the LSC going so that I could complete my research. Thank you to Kim Doty-Harris and Ann Keech for their friendship and help navigating the physics department. Finally, my very special thanks to my parents, Phil \& Sue Owen, my fiancé Robert Wilsey and his parent, Mike \& Kathy Wilsey, for their love and support as I finish this journey. 
Table of Contents

Abstract i

Dedication

Acknowledgements iii

List of Tables $\quad$ v

List of Figures vi vi

$\begin{array}{ll}\text { Chapter 1-Background } & 1\end{array}$

Chapter 2-Materials and General Methods 14

$\begin{array}{lr}\text { Chapter 3-Results } & 29\end{array}$

Chapter 4-Conclustions \& Discussion $\quad 51$

References $\quad 54$ 
List of Tables

Table 1: Comparison of $\mathrm{Kd}_{d} \mathrm{Ca}^{2+}$ values and Hill numbers for different $\mathrm{HTL}$ concentrations .........................................................

Table 2: Comparison of $\mathrm{K}_{d} \mathrm{Ca}^{2+}$ values for different concentrations of $\mathrm{HTL}$.......33

Table 3: Shift in $\mathrm{Ca}^{2+}$ dependent ryanodine binding $\mathrm{K}_{d}$ as a function of redox potential and HTL concentration.........................................35

Table 4: Shift in $\mathrm{Ca}^{2+}$ dependent ryanodine binding $\mathrm{K}_{d}$ as a function of time and HTL concentration........................................................ 37 
List of Figures

Figure 1: The sarcoplasmic reticulum and transverse tubule system of striated

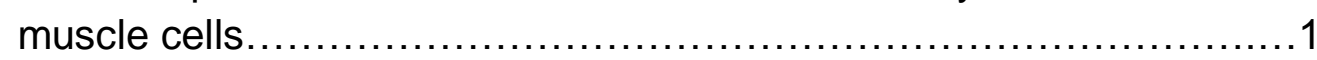

Figure 2: Excitation-contraction model.......................................

Figure 3: 3D reconstruction of the calcium release channel protein ...............5

Figure 4: Model of the $\mathrm{Ca}^{2+}$ release protein gated by $\mathrm{SH}$ oxidation and reduction of three endogenous $\mathrm{SH}$ groups.....................................

Figure 5: Metabolic conversions of Homocysteine and the chemical structures of methionine, Homocysteine, and Hcy-thiolactone.....................10

Figure 6: The reaction of HTL with the $\varepsilon$-amine moiety of protein lysine residues results in a post-translational modification known as $\mathrm{N}-\mathrm{Hcy}$-protein...11

Figure 7: Homocystamides serve as sites of protein radical initiation and concomitant structural changes.....................................12

Figure 8: Derivatization of protein carbonyls with DNPH $\ldots \ldots \ldots \ldots \ldots \ldots \ldots \ldots \ldots \ldots \ldots \ldots \ldots \ldots \ldots$

Figure 9: $\beta$-mercaptoethanol is required to visualize the ryanodine receptor .....23

Figure 10: Determination of the molecular mass of significantly carbonylated

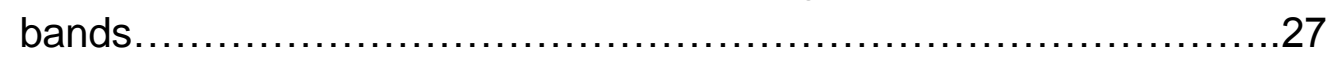

Figure 11: Spot density tool in the analysis tab found in the AlphaEaseFC

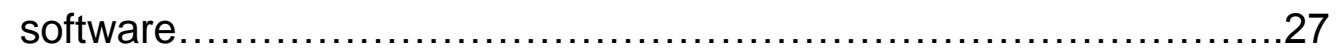

Figure 12: HTL sensitizes RyR2 to $\mathrm{Ca}^{2+}$ dependent activation....................30

Figure 13: Shift in the calcium concentration needed to half maximally activate ryanodine binding in cardiac muscle as a function of $\mathrm{HTL}$ concentration.

Figure 14: HTL and GSH adducts formed after 25 hours do not change the

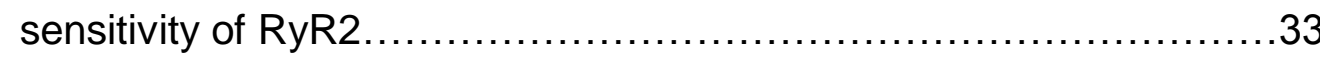

Figure 15: Solution redox potential alters the ability of HTL to sensitize RyR2 to $\mathrm{Ca}^{2+}$ dependent activation

Figure 16: Shift in calcium dependent ryanodine binding after 6 hours of incubation with or without $100 \mathrm{nM} \mathrm{HTL}$ 
Figure 17: Western blot image of RyR2 treated with increasing concentrations of HTL showing increased carbonylation................................38

Figure 18: Carbonylation of RyR2 as a function of HTL concentration............40

Figure 19: Carbonylation as a function of solution redox potential with or without 100nM HTL..................................................... 41

Figure 20: Enhancement of carbonylation by HTL as a function of solution redox potential............................................................ 42

Figure 21: Carbonylation increases as a function of time and HTL..............44

Figure 22: Enhancement of carbonylation by HTL as a function of time ...........45

Figure 23: Carbonylation increases as a function of free $\mathrm{Ca}^{2+}$ with or without 100nM HTL........................................................... 46

Figure 24: Enhancement of carbonylation by $\mathrm{HTL}$ as a function of $\mathrm{Ca}^{2+}$ concentration.

Figure 25: Western blot image of SR treated with DNPH at increasing concentrations of free $\mathrm{Ca}^{2+}$ shows increased carbonylation of multiple proteins .48

Figure 26: Carbonylation of the $205 \mathrm{kDa}$ protein as a function of free $\mathrm{Ca}^{2+}$ concentration. 


\section{Chapter 1: Background}

\subsection{The Contraction of a Muscle Cell}

Vertebrate muscle provides mechanical force upon stimulation and can be separated into three types: skeletal, cardiac and smooth. In muscle cells, filaments called myofibrils are surrounded by the sarcoplasmic reticulum (SR), a net-like membrane that is periodically penetrated by the transverse tubular system (T-tubules) ${ }^{1}$ at intervals of approximately $1.2 \mu \mathrm{m}$ in skeletal muscle fibers and $2.5 \mu \mathrm{m}$ in cardiac ventricles. The initiation of contraction is caused by an electrical excitation, called an action potential, which travels along the surface membrane of the muscle cell and down the T-tubules, allowing the action potential to travel across the surface of the entire muscle fiber rapidly. The time that it takes skeletal muscle to contract is approximately $2-5 \mathrm{~ms}$, whereas cardiac muscle is slightly slower, taking $20-50 \mathrm{~ms}$.

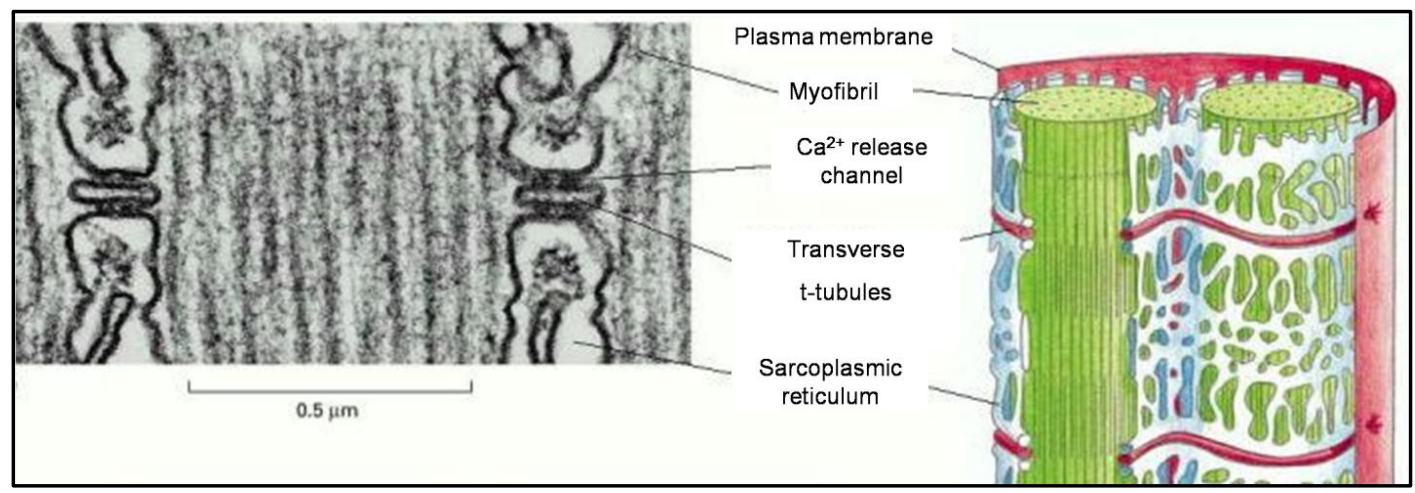

Figure 1: The sarcoplasmic reticulum and transverse tubule system of striated muscle cells². 
T-tubules are separated from the terminal cisternae ${ }^{3}$ of the SR by approximately $10 \mathrm{~nm}$ and the interaction between them is referred to as excitation-contraction coupling (ECC). In this process, three things must happen: the detection of the propagation of an action potential along the T-tubules, the transmission of the information by the Dihydrophridine Receptor (DHPR) to the Calcium Release Channel (CRC), and the release of calcium from the SR. Figure 2 shows a schematic of the flow of calcium out of the SR through the CRC, where it binds to Troponin $\mathrm{C}$ at micro molar concentrations, causing tropomyosin to change its shape and move away from its blocking position. This change uncovers the binding sites on the actin filament for myosin, so that the myosin and actin filaments slide past each other resulting in contraction of the muscle fibers. After calcium is released from the $\mathrm{SR}$, the $\mathrm{Ca}^{2+}-\mathrm{Mg}^{2+}-\mathrm{ATP}$ ase $\left(\mathrm{Ca}^{2+}\right.$ pump), a $110 \mathrm{kDa}$ protein, pumps the calcium back into the lumen of the SR, causing the muscle to relax ${ }^{4}$. 


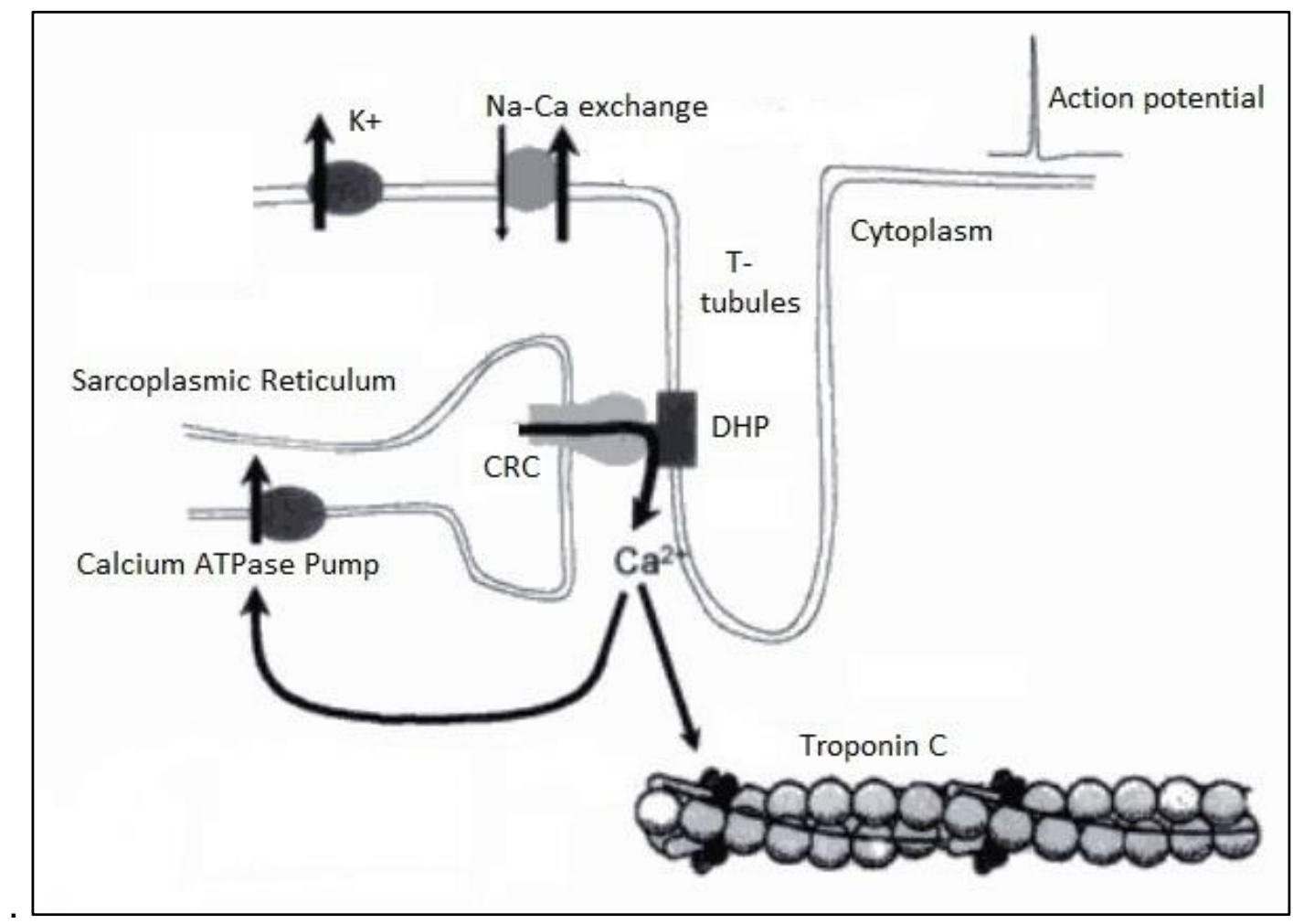

Figure 2: Excitation-contraction model ${ }^{5}$. During the action potential, $\mathrm{Ca}^{2+}$ enters into the cell through the voltage-dependent $\mathrm{Ca}^{2+}$ channel (DHPR) resulting in an increase of cytosolic $\mathrm{Ca}^{2+}$ concentrations to micromolar levels. In human cardiac myocytes, removal of the excess of $\mathrm{Ca}^{2+}$ out of the cytoplasm is accomplished as follows; $70 \%$ by the Sarco/Endoplasmic Reticulum $\mathrm{Ca}^{2+}$ pump, $28 \%$ by the $\mathrm{Na}^{+} /$ $\mathrm{Ca}^{2+}$ exchange protein, and the remaining $2 \%$ is accomplished by the plasmalemmal $\mathrm{Ca}^{2+}$ - ATPase and mitochondrial uniporter ${ }^{11}$.

One of the major differences between cardiac and skeletal muscle is that ECC in cardiac muscle requires a small amount of $\mathrm{Ca}^{2+}$ to cross the T-tubule, whereas in skeletal muscle ECC is independent of extracellular calcium 6 . The activation of the CRC by calcium in cardiac muscle proceeds by a mechanism known as Calcium Induced Calcium Release. ${ }^{7}$ 


\subsection{Impact of Abnormal Intracellular $\mathrm{Ca}^{2+}$ Cycling}

In cardiac muscle there are additional proteins not found in skeletal muscle. Since $\mathrm{Ca}^{2+}$ enters the cell through the DHPR to initiate cardiac muscle contraction, there must be a mechanism for purging $\mathrm{Ca}^{2+}$ from the cell. The $\mathrm{Na}^{+} /$ $\mathrm{Ca}^{2+}$ exchange protein (NCX) moves three $\mathrm{Na}^{+}$ions into the cell and one $\mathrm{Ca}^{2+}$ ion out of the cell. This is the primary mechanism for maintaining low intracellular $\mathrm{Ca}^{2+}$ concentrations in spite of the fact that $\mathrm{Ca}^{2+}$ enters the cell on each beat of the heart.

Problems with intracellular $\mathrm{Ca}^{2+}$ cycling have been associated with heart failure, ischemic heart disease, and several genetic forms of arrhythmias ${ }^{8}$. Heart failure is characterized by abnormal intracellular $\mathrm{Ca}^{2+}$ cycling that leads to progressive deterioration of cardiac function. Associated with heart failure is the inability of the SR to build up an adequate $\mathrm{Ca}^{2+}$ load required for generating contraction, due to an increased $\mathrm{Ca}^{2+}$ leak connected with the $\mathrm{Ca}^{2+}$ release channel. An abnormal $\mathrm{Ca}^{2+}$ leak from the SR during the relaxation phase of the heart, when the cytosolic $\mathrm{Ca}^{2+}$ concentrations should be low, have been shown to cause arrhythmias known as delayed afterdepolarizations (DADs) ${ }^{9}$. When intracellular $\mathrm{Ca}^{2+}$ levels rise the $\mathrm{NCX}$ assists in removing the $\mathrm{Ca}^{2+}$ from the cell, which results in the influx of sodium and can lead to a depolarization of the extracellular membrane. This unsynchronized action potential can generate arrhythmias. CRCs that have a diastolic $\mathrm{Ca}^{2+}$ leak have consequently become a therapeutic target. 


\subsection{Calcium Release Channel}

The calcium release channel is a cation-selective trans-membrane protein that is thought to be a homotetramer, with each of its subunits having a molecular mass of about $565 \mathrm{kDa}$. These subunits are arranged in a quatrefoil shape, 22 to $27 \mathrm{~nm}$ on each side, with a $2 \mathrm{~nm}$ hole in the center ${ }^{10}$. The plant alkaloid ryanodine binds to this protein with high affinity and high selectivity when the channel is in its open state ${ }^{11}$. Because of this, the channel is commonly referred to as the ryanodine receptor (RyR). The RyR has three isoforms known as RyR1, RyR2 and RyR3, each encoded by a separate gene. All three isoforms appear in brain tissue; however, RyR1 is found predominately in skeletal muscle, while RyR2 is found primarily in cardiac muscle. These three isoforms share a $66-70 \%$ homology in amino acid sequence ${ }^{12}$.

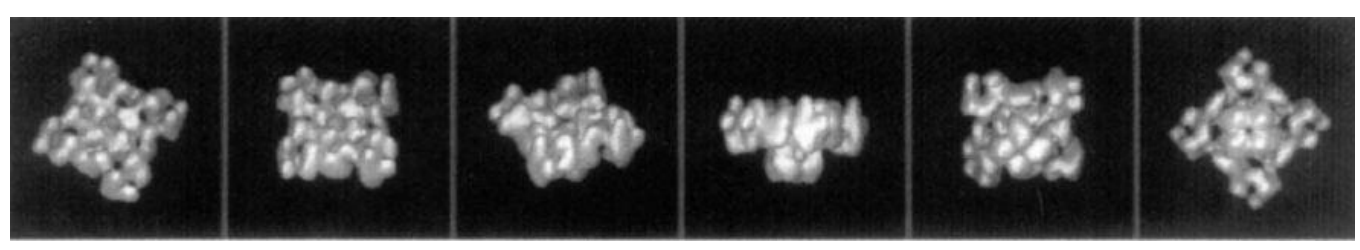

Figure 3: 3D reconstruction of the calcium release channel protein (commonly known as the ryanodine receptor) ${ }^{13}$

\subsection{Modification of $\mathrm{Ca}^{2+}$ Release}

$\mathrm{Ca}^{2+}$ has a biphasic role in the regulation of RyR. Low micromolar concentrations of cytoplasmic $\mathrm{Ca}^{2+}$ stimulate the channel while high concentrations $(>1 \mathrm{mM})$ inhibit the channel ${ }^{14}$. This bell shaped $\mathrm{Ca}^{2+}$ dependence curve has been 
hypothesized to result from two different binding sites: a high affinity site that opens the channel and a low affinity site that inhibits release ${ }^{15}$ While a rise in $\mathrm{Ca}^{2+}$ concentration in the cytosol is the principle factor stimulating the $\mathrm{CRC}^{16}$ in cardiac muscle, in skeletal muscle, where ECC is independent of extracellular $\mathrm{Ca}^{2+}$, another mechanism of information transfer must be present. It is generally believed that there is some type of conformational coupling between the DHPR and the Ryanodine Receptor in skeletal muscle, but the precise mechanism is unknown.

There is direct evidence, however, for the existence, location and function of hyperreactive thiols, which have been reported in both skeletal ${ }^{17}$ and cardiac muscle ${ }^{18}$. Figure 4 shows a proposed model of the $\mathrm{Ca}^{2+}$ release channel that is regulated by several classes of sulfhydryl groups existing in close proximity and able to form mixed disulfides. Oxidation of these hyperreactive sulfhydryl groups to a disulfide linkage, which opens the channel $\left(S_{1}-S_{2}\right)$, is then followed by thioldisulfide exchange $\left(\mathrm{S}_{2}-\mathrm{S}_{3}\right)$ that closes the channel, and finally, reduction of the disulfide bond by the cellular reduced (redox) environment, which resets the redox status.

In support of this model, it has been shown that the CRC has a welldefined reduction potential that is sensitive to the cellular environment. ${ }^{19}$ Channel activators lower the redox potential, making the value more negative, which favors the oxidation of thiols and the opening of the channel, while channel inhibitors increase the redox potential to more positive values, which favors the 
reduction of disulfides and the closure of the channel. During oxidative stress or ischemia, these hyperreactive thiols could oxidize and alter the $\mathrm{Ca}^{2+}$ sensitivity of the $\mathrm{CRC}$, allowing small changes in the calcium concentrations to contribute to significant activation and release of $\mathrm{Ca}^{2+}$.
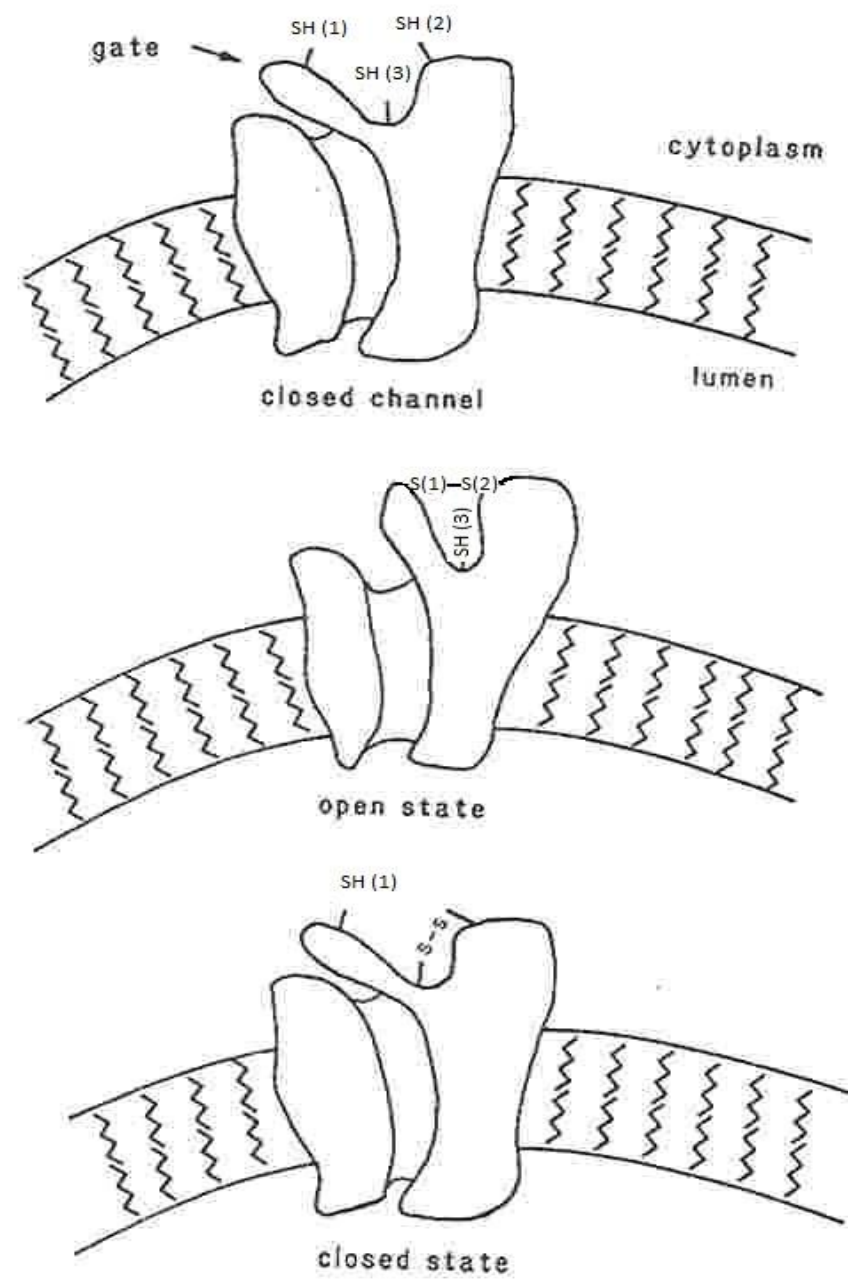

Figure 4: Model of the $\mathrm{Ca}^{2+}$ release protein gated by $\mathrm{SH}$ oxidation and reduction of three endogenous $\mathrm{SH}$ groups ${ }^{20}$ 
Glutathione (GSH) is part of an antioxidant system and plays an important part in maintaining the cellular redox status. Along with antioxidant vitamins and enzymes it shares the job of scavenging peroxide, singlet oxygen and other free radicals, and it is the most abundant non-protein thiol source in the muscle cell ${ }^{21}$. The eye lens has the highest GSH concentrations at $\sim 10 \mathrm{mM}$, whereas muscle has about $1-2 \mathrm{mM}^{22}$. During excessive production of reactive oxygen species (ROS), GSH donates a pair of electrons to a hydroperoxide, resulting in $2 \mathrm{GSH}$ being oxidized to 1 glutathione disulfide (GSSG). The GSSG can then be reduced back to GSH by NADPH, which is catalyzed by glutathione reductase (GR). When production of the ROS overwhelms the recycling capacity of the GR, GSSG levels rise, resulting in a decrease of the GSH/GSSG ratio and a more oxidized environment.

While GSSG by itself is an activator of the channel, and GSH is a known inhibitor, it has been reported that the ratio of GSH/GSSG rather than the total GSH or total GSSG concentrations determine the response of the RyR ${ }^{23}$. The typical mammalian cell ratio of [GSH]/[GSSG] in the cytosol is $\geq 30: 1$, resulting in a reduction potential of approximately $-230 \mathrm{mV}^{24}$. Trans-membrane redox potential differences are on the order of $50 \mathrm{mV}$, with the lumen of the SR being more oxidized than the cytosol ${ }^{30}$. 


\subsection{Homocysteine and Homocysteine Thiolactone}

Circulating molecules, commonly referred to as biomarkers, can serve as a means for diagnostics during the diseased state or can identify the perturbations that precede the disease. One of these biomarkers, Homocysteine (Hcy), is an accepted independent risk factor for several pathologies including cardiovascular disease, osteoporosis, Alzheimer's disease and renal failure ${ }^{25,26}$. First observed by Kilmer McCully in $1969^{27}$, Hcy, has been the subject of numerous clinical, experimental, and epidemiological studies seeking to explain the molecular mechanisms underlying the link between the rise (a mild case of hyperhomocysteinemia has a range of concentrations in plasma of $15-50 \mu \mathrm{mol} / /^{28}$ ) in concentration of Hcy and this vast array of diseases.

Over 30 studies have been conducted by different groups including; the Homocysteine Studies Collaboration group, and the Vitamin Intervention for Stroke Prevention group, often with conflicting results. As an example of the conflicting results published, a study performed in 1999 found a $5 \mu \mathrm{mol} / /$ rise in plasma Homocysteine levels leads to a $19 \%$ increase in stroke risk and a $25 \%$ rise in coronary artery disease ${ }^{28}$. However in 2004 , the trial of 3,680 randomized subjects found no change for risk of coronary events with a reduction of a baseline plasma Homocysteine level by $2 \mu \mathrm{mol} / \mathrm{l}$. Moreover, homocysteine is a universal intermediate in methionine metabolism and is formed in all human organs. In mammals, dietary methionine, an essential amino acid, is the only source of Hcy. Elevated levels of Hcy can be caused by a variety of factors, 
including genetic defects or nutritional and dietary status such as methionine-rich diets. ${ }^{29}$ Although the cytotoxic effects of Hcy excess have been confirmed in many biological model systems, the underlying mechanisms are unknown, and whether toxicity is caused by Hcy itself or by a Hcy metabolite, is not entirely clear.

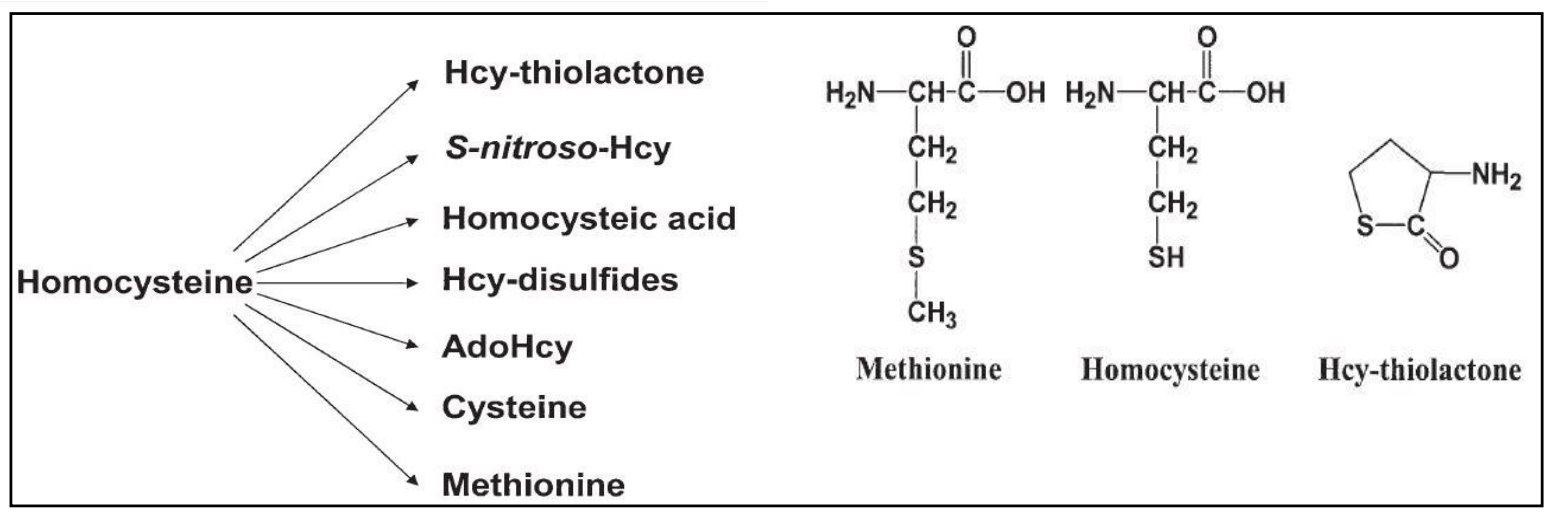

Figure 5: Metabolic conversions of Homocysteine and the chemical structures of methionine, Homocysteine, and Hcy-thiolactone. ${ }^{30}$

The thioester Homocysteine Thiolactone (HTL) is one of many metabolites of Homocysteine and is generated via an error-editing mechanism of methionine tRNA synthetase. Due to its ability to create a 5 -membered ring, HTL is remarkably stable (with a half life of $\sim 25$ hours $^{31}$ ) to hydrolysis at physiological temperatures and $\mathrm{pH}$. Like all thioesters, $\mathrm{HTL}$ absorbs UV light with a maximum at $240 \mathrm{~nm}$ and $\varepsilon \sim 5000 \mathrm{M}^{-1} \mathrm{~cm}^{-1}$ in water, and has an unusually low $\mathrm{pK}_{\mathrm{a}}$ of 7.1 for its alpha amino group, which allows it to freely diffuse through cell membranes ${ }^{32}$. 
$H T L$ reacts readily with the $\varepsilon$-amine of Lys residues to form isopeptide bonds, as shown in figure 6.

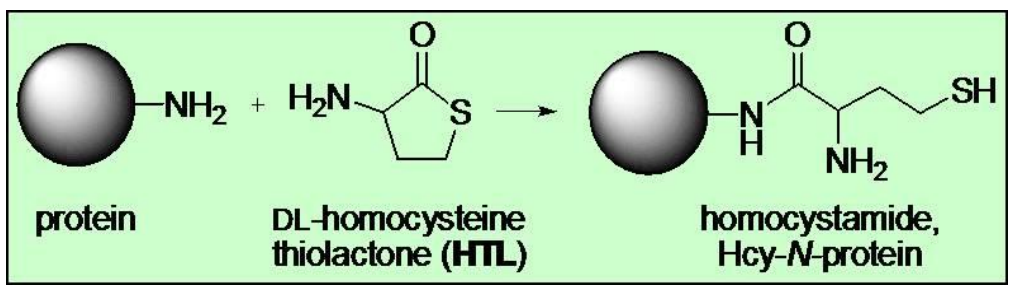

Figure 6: The reaction of HTL with the $\varepsilon$-amine moiety of protein lysine residues results in a post-translational modification known as N-Hcy-protein.

\subsection{Chemical Mechanism of Oxidative Damage to Proteins}

Two possible mechanisms have been proposed to explain how homocystamides can lead to oxidative damage and loss in protein function. One hypothesis postulates free radical and oxidative damage to proteins via reactive oxygen species (ROS) generation upon disulfide bond formation. The other hypothesis involves ${ }^{\alpha} \mathrm{C}$ amino acid radical formation ${ }^{2}$. It is widely accepted that a majority of protein backbone cleavage and related damage occurs via alpha-carbon radicals of amino acid residues. It has also been shown that cysteinyl residues and glutathione may aid the formation of alpha-carbon radicals on protein residue ${ }^{33}$. The alpha-carbon radical can also go on to create a reactive carbonyl species (RCS) as depicted in figure 7. In this scheme, homocystamides may serve as sites of protein-radical initiation followed by kinetically-favored hydrogen atom transfer (HAT), which should promote carbonyl formation. 


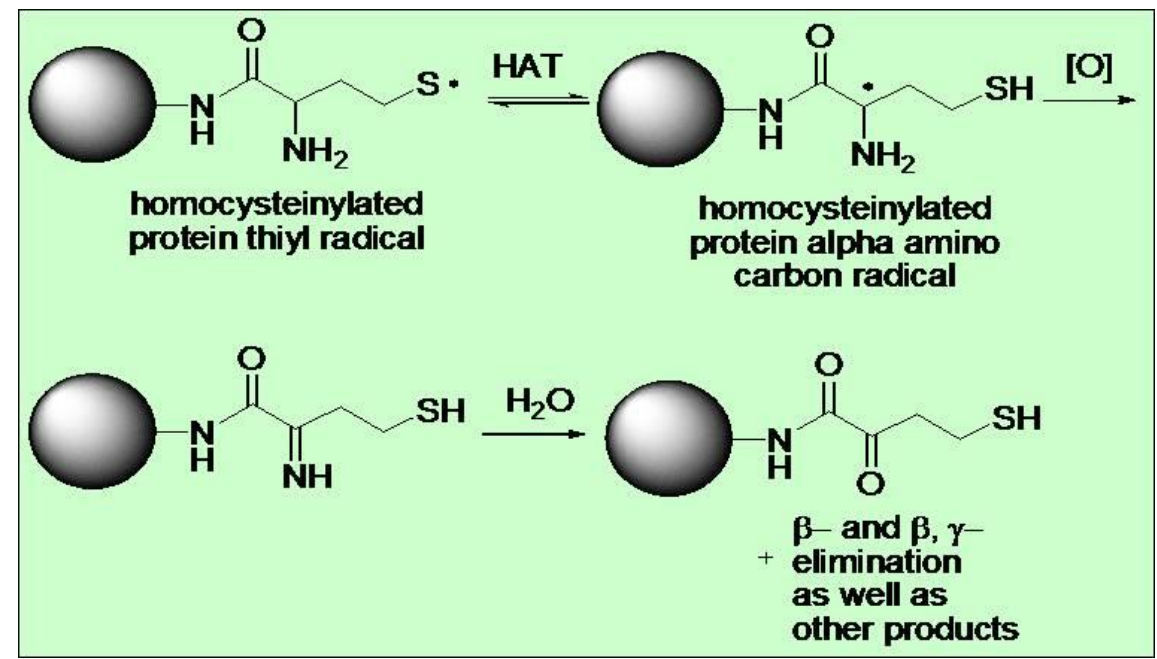

Figure 7: Homocystamides serve as sites of protein radical initiation and concomitant structural changes.

\subsection{Previous studies of carbonyl modification of SR proteins}

In 2011 Marks and colleagues published a study that implicated carbonyl

modification of RyR1 to age related loss of muscle mass and force in the ageing mouse model ${ }^{34}$. They observed an increase of 4 fold of the amount of carbonyls found on the RyR1 isolated from 24 month old mice as compared to the younger 3-6 month old mice. They concluded that this oxidative damage plays an important role in the aging mechanism. Carbonyl formation is irreversible. There are currently no known enzymes that are capable of breaking RCS adducts after they are formed on proteins in mammalian cells ${ }^{35}$.

RCS however, will not react indiscriminately with all available residues and certain residues have been shown to be more susceptible to carbonylation than others $^{33}$. Bidasee and colleagues have studied the formation of RCS in a diabetic 
rat model where the RCS are found in the serum and urine of the animal due to an increased glucose and fatty acid oxidation, increased degradation of ketotic products, and increased triose pathway flux ${ }^{36}$. They have identified via mass spectrometry and site-directed mutagenesis that in the case of the SERCA2a $\mathrm{Ca}^{2+}$-pump, the major protein found in the SR, four key residues ( $\operatorname{Arg} 164$, Lys 476, Lys 481, and Arg 636) are more susceptible to carbonylation and that the carbonylation of these residues contributes to the $\mathrm{Ca}^{2+}$-pump activity loss (decrease in ATPase activity) and diastolic dysfunction ${ }^{37}$. They hypothesized that these basic residues, with low pKa values, would be more likely to undergo carbonylation than residues with a higher pKa values, because a greater fraction would exist in the deprotonated state at a physiological $\mathrm{pH}$ of 7.4 , which would render them more susceptible to modification ${ }^{38}$. In the same model, Bidasee and colleagues have simulated the effect that carbonyl adducts could have on RyR2 by site-directed mutagenesis mimicking the simultaneous charge neutralization and increase in bulk induced by carbonylation that would be expected to occur. They chose amino acids from fragments that had be improperly digested by trypsin ${ }^{39}$, indicating a modification due to streptozotocin (STZ)-induced diabetes that would mimic carbonyl adduct formation. They found that mutations that simulated carbonylation at Lys2190 or Lys2887 (lysine to tyrosine or tryptophan) would enhance the $\mathrm{Ca}^{2+}$ sensitivity of RyR2 and mutations at Arg4462 or Arg4682 (arginine to tyrosine or tryptophan) likely would reduce the $\mathrm{Ca}^{2+}$ sensitivity of $R y R 2^{34}$. 


\section{Chapter 2: Materials and General Methods}

\subsection{Materials}

Tritium-labeled ryanodine $\left(\left[{ }^{3} \mathrm{H}\right]\right.$-ryanodine $)$ was purchased from PerkinElmer Life \& Analytical Sciences, Boston Massachusetts, and stored in the freezer at $-18^{\circ} \mathrm{C}$ and shielded from light. Unlabeled ryanodine was purchased from Calbiochem (a division of Merck KGaA, Darmstadt, Germany). A stock solution was prepared at $10 \mathrm{mM}$ in $50 \%$ Methanol/deionized distilled nanopure water. Sheep hearts were a gift from Dr. Kent Thornburg, Heart Research Center, Oregon Health and Science University, Portland, Oregon.

Ethylene Glycol Tetraacetic Acid (EGTA) was purchased from Research Organics, Cleveland, Ohio, and prepared in deionized distilled nanopure water, adjusted to $\mathrm{pH} 7.0$ with the addition of potassium hydroxide $(\mathrm{KOH})$ and stored at room temperature. CytoScint scintillation fluid was purchased from MP Biomedicals, Costa Mesa, California. Homocysteine Thiolactone (HTL) was a gift from Dr. Robert M. Strongin, Department of Chemistry, Portland State University, Portland, Oregon. HTL stock solution was freshly prepared at $~ 30 \mu \mathrm{M}$ in buffer containing $250 \mathrm{mM} \mathrm{KCl}, 15 \mathrm{mM} \mathrm{NaCl}$, and 20mM Piperazine-1,4-bis(2ethanesulfonic Acid (PIPES) set to $\mathrm{pH} 7.4$ with $\mathrm{KOH}$ unless otherwise noted.

Acrylamide/Bis 37.5:1 premixed powder, Immun-Blot PVDF membrane for protein blotting, detergent compatible (DC) Protein Assay kit, and dual color precision plus protein standards were obtained from Bio Rad. Oxyblot ${ }^{\mathrm{TM}}$ Protein Oxidation Detection Kit was purchased from Chemicon/Millipore. Anti-Ryanodine 
Receptor 2 antibody (C3-33) was obtained from GeneTex, and horseradish peroxidase labeled goat anti-mouse secondary antibody was obtained from Santa Cruz Biotech. Glutathione in both its oxidized and reduced form was prepared on ice in ice-cold deionized distilled nanopure water containing $10 \mu \mathrm{M}$ EGTA at a concentration of $0.5 \mathrm{M}$. Once the $\mathrm{pH}$ was adjusted to $\mathrm{pH} 7.0$, aliquots were frozen in liquid $\mathrm{N}_{2}$. All other chemicals were purchased from Sigma-Aldrich Corporation, St. Louis.

\subsection{Cardiac SR Preparation}

Cardiac SR vesicles were isolated from sheep hearts obtained from OHSU based on the method of Meissner and Henderson. ${ }^{40}$ Unless otherwise stated, all procedures were carried out in at $4^{\circ} \mathrm{C}$. Once the heart was removed from the sheep, it was briefly immersed in ice cold buffer containing $300 \mathrm{mM}$ Sucrose, 10mM PIPES, $0.5 \mathrm{mM}$ PMSF, $1 \mu \mathrm{g} / \mathrm{ml}$ Leupeptin at $\mathrm{pH} 7.4$ with $\mathrm{KOH}$ (Cardiac Buffer A). The atria and other connective and fatty tissue were removed and the remaining ventricles were minced into small pieces to be blended at high speed in a waring blender for 20 seconds.

After a 30-second rest period, the solution was blended again on high for 20 seconds. The resultant solution was centrifuged at 9,000 $\mathrm{xg}$ in the large Fiberlite $\mathrm{F}-14$ rotor at $4^{\circ} \mathrm{C}$. The supernatant was then filtered through two layers of cheesecloth and spun at $44,000 \times \mathrm{g}$ for 75 minutes in a type 19 rotor at $4^{\circ} \mathrm{C}$. The resultant pellet was homogenized in Cardiac Buffer A and spun at 25,000 x g 
for 30 minutes at $4^{\circ} \mathrm{C}$. The resulting SR pellet was homogenized in a buffer containing $100 \mathrm{mM}$ Sucrose, $5 \mathrm{mM}$ HEPES and adjusted to $\mathrm{pH} 7.2$ with tris(hydroxymethyl) aminomethane-base (Tris-base). Once protein concentration was determined, and diluted if needed to approximately $20 \mathrm{mg} / \mathrm{ml}$, the crude cardiac SR aliquots were stored in liquid $\mathrm{N}_{2}$.

\subsection{Protein Determination}

Large volume, crude protein concentrations of the SR were determined by the method of Kalckar ${ }^{41}$. The absorbance peak at $280 \mathrm{~nm}$ is mainly due to the presence of tyrosine and tryptophan and the peak at $230 \mathrm{~nm}$ is mainly due to the peptide bond of the protein backbone. Using this information, absorption was measured on an Agilent 8453 UV-Visible photodiode array spectrophotometer at $230 \mathrm{~nm}$ and $280 \mathrm{~nm}$. Data were also collected at $260 \mathrm{~nm}$ in order to correct for nucleic acids using equations 1 and 2 . The process was repeated twice, and the average protein concentration was calculated.

$$
[S R]_{\mathrm{mg} / \mathrm{ml}}=1.45 \times \mathrm{Abs}_{280}-0.74 \times \mathrm{Abs}_{260}
$$

$$
[\mathrm{SR}]_{\mathrm{mg} / \mathrm{ml}=}=0.185 \times \mathrm{Abs}_{230}-0.748 \times \mathrm{Abs}_{260}
$$

When determining the protein concentrations of small volumes $(<200 \mu l)$ an assay kit called, Bio-rad DC (detergent compatible) assay, based on the method 
of Lowry ${ }^{42}$ was used. Small aliquots of the crude protein, and purchased BSA protein standard were diluted to a final volume of $100 \mu l$. The volume was then reacted with solutions provided in the kit and incubated on an orbital shaker for $15 \mathrm{~min}$. Absorbance at $740 \mathrm{~nm}$ was then recorded for each sample and a standard curve equation was calculated.

\subsection{Determination of $\mathrm{Ca}^{2+}$ stock solutions}

Free $\mathrm{Ca}^{2+}$ in experimental solutions were determined using a $\mathrm{Ca}^{2+}$ ion selective electrodes that consisting of a liquid ion exchanger embedded in a polyvinyl chloride (PVC) membrane which has direct contact with a graphite rod ${ }^{43,44}$. When the functionalized membrane end is immersed into a solution with free $\mathrm{Ca}^{2+}$ ions, the $\mathrm{Ca}^{2+}$ ions diffuse into the membrane causing an internal positive charge within the membrane. At the same time, a negative charge builds up on the solution side of the membrane (due to the loss of positive $\mathrm{Ca}^{2+}$ ions) until eventually, the diffusion pressure and the electrostatic forces are balanced and the diffusion stops. The resulting difference in charge across the membrane is the membrane potential and when compared to a reference electrode in the solution without the functionalized membrane, the membrane potential can be measured by a high impedance electrical meter with $\mathrm{mV}$ capability.

In the case of potentiomeric measurements with ion selective electrodes where there aren't any redox reactions occurring, the modified Nernst equation, shown as Equation 3, can be used. 


$$
E=E^{\circ}+\left(\frac{R T}{z F}\right) \ln \left[C a^{2+}\right]
$$

Where $E$ is the measured membrane potential, $E^{0}$ is the sum of the potentials on the electrode side of the membrane and any other junction potentials in the system. The $\left(\frac{R T}{z F}\right)$ term includes; $R$ the gas constant $\left(8.31 \mathrm{~J} / \mathrm{mol}^{*} \mathrm{~K}\right), T$ the temperature (295K), $z$ the species charge $\left(2\right.$ for $\left.\mathrm{Ca}^{2+}\right)$, and $F$ the Faraday constant $(96,485$ Coulomb/mol). The result of that term including a 2.3 factor for conversion to base $\log _{10}$, is $0.029 \mathrm{~V}$ resulting in the following equation.

$$
E=E^{\circ}+29 * \log _{10}\left[\mathrm{Ca}^{2+}\right](m V)
$$

Where $E$ is the measured potential in $\mathrm{mV}$. This equation describes a line with a slope of $29 \mathrm{mV} /$ decade change of [ $\left.\mathrm{Ca}^{2+}\right]$. Each time a new probe is put into use for the first time after fabrication and conditioning, the response to $\left[\mathrm{Ca}^{2+}\right]$ is verified to be linear and with a near Nernstian slope value of $29 \mathrm{mV}$.

\subsection{Equilibrium Ryanodine Binding Assay}

The molecule ryanodine binds with nanomolar affinity to a single class of proteins near the junctional region of the $\mathrm{SR}^{45}$ under certain conditions. With a few exceptions, such as silver, CRC activators stimulate ryanodine binding, whereas compounds that inhibit the CRC inhibit binding. Tritium-labeled ryanodine $\left(\left[{ }^{3} \mathrm{H}\right]-\right.$ 
ryanodine) binding assays were carried out at a $\left[{ }^{3} \mathrm{H}\right]$ ryanodine concentration of $1 \mathrm{nM}$, and $14 \mathrm{nM}$ unlabeled ryanodine for skeletal $\mathrm{SR}$, and a $\left[{ }^{3} \mathrm{H}\right]$ ryanodine concentration of $2 \mathrm{nM}$, and $13 \mathrm{nM}$ unlabeled ryanodine for cardiac SR.

SR vesicles $(0.5 \mathrm{mg} / \mathrm{ml})$ were incubated in a buffer containing $250 \mathrm{mM} \mathrm{KCl}$, $15 \mathrm{mM} \mathrm{NaCl}$, and 20mM Piperazine-1,4-bis(2-ethanesulfonic Acid (PIPES), set at $\mathrm{pH} 7.4$ and $37^{\circ}$ Celsius for at least 3 hours. The binding reaction was quenched by rapid filtration through Whatman glass fiber filters using a Brandel cell harvester. Filters were washed twice with approximately $4 \mathrm{ml}$ of buffer containing $250 \mathrm{mM} \mathrm{KCl}, 15 \mathrm{mM} \mathrm{NaCl}, 20 \mathrm{mM}$ tris-(hydroxymethyl)- aminomethane (TRIS), and $100 \mu \mathrm{M} \mathrm{CaCl}_{2}$ at $\mathrm{pH} 7.1(\mathrm{HCl})$. These filters were then dried in an oven at $50^{\circ} \mathrm{C}$ for two hours, then incubated with agitation in $3 \mathrm{ml}$ of CytoScint scintillation fluid for one hour.

Radioactivity was counted by a Beckman LS 6000 scintillation counter with an efficiency of approximately $55 \%$. Nonspecific binding was measured in the presence of $200 \mathrm{nM}$ unlabeled ryanodine, and $4 \mathrm{mM}$ ethylene glycol tetra acetic acid (EGTA). Total specific activity was determined by adding an aliquot of experimental $\left[{ }^{3} \mathrm{H}\right]$-ryanodine buffer solution to scintillation fluid and counting the sample.

\subsection{Hill Analysis}

Calcium dependent ryanodine binding measurements were fit to the Hill equation 


$$
B=B_{\max } \frac{[x]^{n}}{k_{d}+[x]^{n}}
$$

where $B_{\max }$ is the maximum binding, $[x]$ is the free $\mathrm{Ca}^{2+}$ concentration determined with the computer program "Bound and Determined" or measured with a $\mathrm{Ca}^{2+}$ electrode, $k_{d}$ is the dissociation constant of the $\mathrm{Ca}^{2+}$ binding site, and $n$ is the Hill coefficient. The graphing software SigmaPlot was used to determine the best fit parameters for the half maximal binding concentration ( $\left.E_{50}\right)$, which was calculated by equation 6 .

$$
E C_{50}=k_{d}^{\left(\frac{1}{n}\right)}
$$

\subsection{Four Parameter Logistic Curve}

The $K_{d}$ values obtained from the calcium dependent ryanodine binding measurements as a function of HTL concentration were fit to the four parameter logistic curve equation.

$$
Y=\min +\frac{\max -\min }{1+\left(\frac{x}{E C_{50}}\right)^{\text {Hillslope }}}
$$

\subsection{Redox Potential}

To study the effects of channel modulators in more reduced or oxidized environments, it is possible to mimic the cellular redox status by using various concentrations of GSH and GSSG determined by the following equation ${ }^{46}$ : 


$$
E_{\text {solution }}=E^{\circ}+2.3 \frac{R T}{F}\left(7.0-p H_{\text {actual }}\right)+2.3 \frac{R T}{n F} \log \frac{[G S S G]}{[G S H]^{2}}
$$

(Equation 8)

where $E_{\text {solution }}$ is the redox potential of the solution, $E^{\circ}$ is the standard potential of glutathione $(-0.24 \mathrm{~V}), p H_{\text {actual }}$ is the $\mathrm{pH}$ of the buffer, $R$ is the gas constant (8.31 $\left.\operatorname{deg}^{-1} \mathrm{~mol}^{-1}\right), T$ is the absolute temperature $(\mathrm{K}), n$ is the number of electrons transferred ( $\mathrm{n}=2$ for glutathione) and $F$ is the Faraday constant $(96406 \mathrm{~J} / \mathrm{V})$.

\subsection{Detection of carbonyl groups with 2,4-dinitrophenylhydrazine (DNPH)}

2,4-Dinitrophenylhydrazine (DNPH) can be used to detect the carbonyl functionality of a ketone or aldehyde functional group in the protein side chains by derivatization to 2,4-dinitrophenylhydrazone (DNPhydrazone). DNPH does not react with other carbonyl-containing functional groups such as carboxylic acids, amides, and esters.

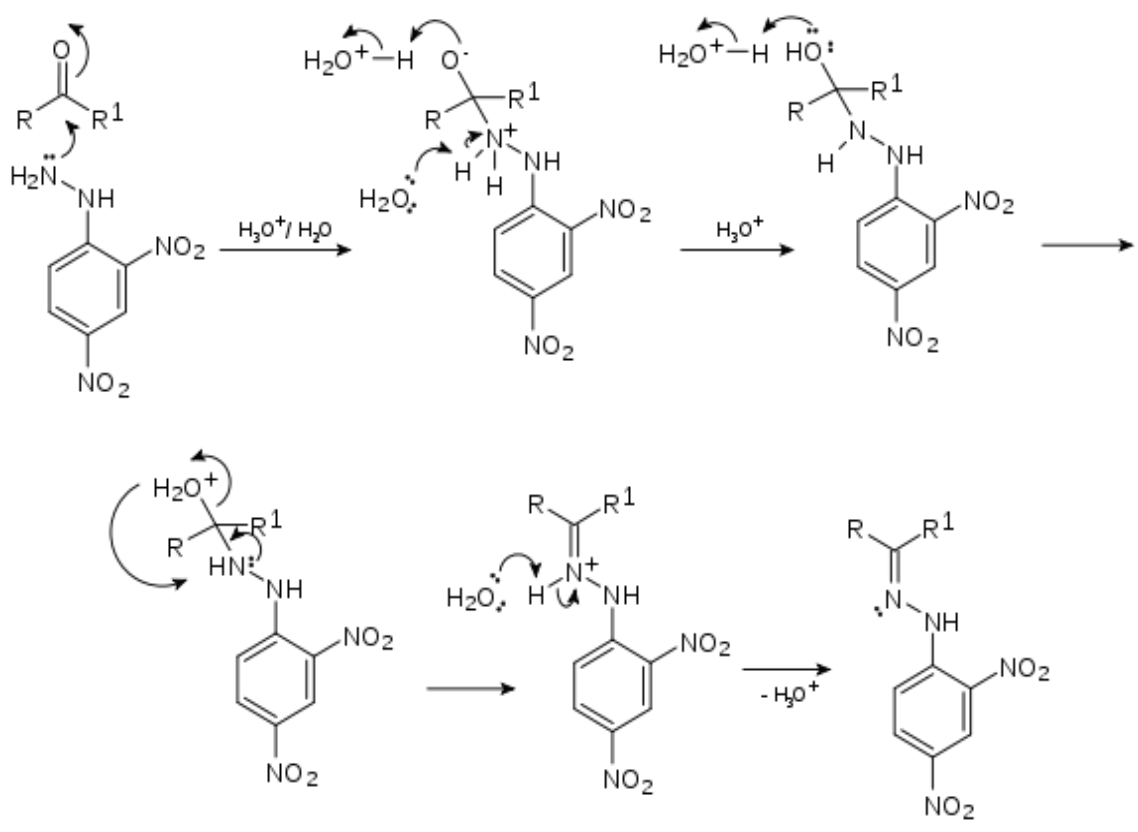

Figure 8: Derivatization of protein carbonyls with DNPH 
All procedures for derivatization of protein carbonyls with DNPH and subsequent detection using the Oxyblot ${ }^{\mathrm{TM}}$ Protein Oxidation Detection Kit (Millipore) follow the procedure as outlined in the kit brochures with the following two exceptions. The 10X-DNPH derivatization solution was prepared as $100 \mathrm{mM}$ in $100 \%$ trifluoroacetic acid (TFA) and diluted ten times with the addition of 9 volumes of water just prior to use, instead of in $2 \mathrm{~N}$ hydrochloric acid $(\mathrm{HCl})^{47}$. The second exception was the use of a non-commercial neutralization solution, which was prepared containing $2 \mathrm{M} \mathrm{TRIS} / 30 \%$ Glycerol (same as in kit).

The protein sample was briefly washed three times with deionized/distilled water and then was derivatized by adding $1 \mathrm{mM}$ DNPH solution. The reaction was allowed to proceed at room temperature for 20 minutes before an equal volume of neutralization solution was added to the $1 \mathrm{X}$ DNPH solution. Care was taken to not allow the reaction to proceed for more than 30 minutes to prevent side reactions other than hydrazone linkages to occur.

\subsection{SDS-PAGE}

Protein samples were prepared for separation via SDS-PAGE by addition of SDS solution to sample, resulting in a final concentration of $8 \%(w / v)$ SDS. After vortexing, samples were spun on a table top centrifuge at $14,000 \mathrm{rpm}$ for 5 minutes to spin down any non-solubilized proteins. The resultant supernatant was split into two fractions. One fraction was used to determine the total protein 
concentration, and the second fraction was loaded on the gel after sample preparation.

Due to the loss of sensitivity of the DNPH labeling when the protein sample was boiled before separation by SDS-PAGE, an alternative method of sample preparation was used. This method consisted of solubilizing the sample at a final concentration of $8 \%(w / v)$ SDS followed by a one hour incubation at room temperature with $3 \%(\mathrm{v} / \mathrm{v}) \beta$-mercaptoethanol. This allowed the RyR2 to enter the gel during electrophoreses.

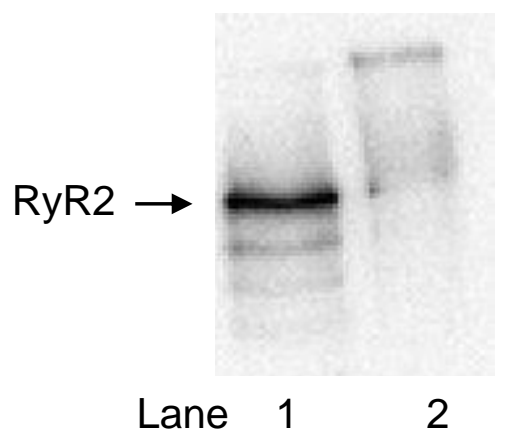

Figure 9: $\beta$-mercaptoethanol is required to visualize the Ryanodine Receptor. The signal in lane 1 shows the antibody labeling of RyR2 from a sample that underwent the alternative method described with $8 \%(\mathrm{w} / \mathrm{v})$ SDS followed by a one hour incubation at room temperature with $3 \%(\mathrm{v} / \mathrm{v}) \beta$-mercaptoethanol. In lane 2 the sample was prepared only with $8 \%(w / v)$ SDS. After the sample was separated on the 3-8\% SDS-PAGE, the protein was electrophoretically transferred to the PVDF membrane at a constant $15 \mathrm{~V}$ for 16 hours at $5^{\circ} \mathrm{C}$. Membrane was then blocked for 1 hour with Tris Buffered Saline (TBS) containing $5 \%$ nonfat dry milk at $23^{\circ} \mathrm{C}$ with agitation. Membranes were then incubated overnight at 1:7000 with a monoclonal antibody to RyR2 residues. Washing was performed in TBS containing $0.1 \%$ Tween-20, 4 times, each time for 5 minutes at room temperature. The membrane then was incubated with a Horse Radish Peroxidase (HRP) conjugated secondary antibody against mouse $(1: 10,000)$ for 1 hour. After washing, the membrane was then incubated with enhanced chemiluminescence detection reagent, before being imaged. 
After each sample's total protein was determined, $15 \mu \mathrm{g}$ per condition was loaded on a Bis-Tris 3-8\% gradient gel. In addition to the appropriate acrylamide/bis acrylamide to water ratio, each separating gel consisted of $400 \mathrm{mM}$ Tris, $0.1 \%$ SDS, $1 \mathrm{mg}$ of ammonium persulfate (APS) and $5 \mathrm{mM}$ Tetramethylethylenediamine (TEMED) at $\mathrm{pH} 8.8$ and was poured with a Hoefer Scientific Instruments (San Francisco, CA) gradient maker. The stacking gel consisted of $3 \%$ acrylamide/bis acrylamide to water ratio along with $5 \mathrm{mM}$ Tris, $0.1 \%$ SDS, $1 \mathrm{mg}$ of APS and $5 \mathrm{mM}$ TEMED at $\mathrm{pH}$ 6.8. Along with samples, $8 \mu \mathrm{l}$ of Precision plus, pre-stained, high molecular weight protein standard (Bio-Rad) was loaded in one well of each gel. The gel was run at $200 \mathrm{~V}$ for 50 minutes for protein separation in an ice bath. Under these conditions the dye front runs off the gel.

\subsection{Western Blot}

Pre-wet polyvinylidene difluoride (PVDF) membrane (Bio-Rad) via analytical grade Methanol, gel, filter paper, and sponges were soaked in Towbin Transfer Buffer $^{48}$ (25mM Tris-base, 192mM glycin, 20\% Methanol (v/v), 0.025\% SDS $(w / v))$ for 20 minutes. Protein bands were electrophoretically transferred to the membrane at a constant $15 \mathrm{~V}$ for 16 hours using a Tank Blot Transfer Apparatus (Bio-Rad Laboratories, Hercules, CA) at $5^{\circ} \mathrm{C}$. Once transferred, the membrane was blocked for 1 hour with a Tris Buffered Saline (TBS) containing 200mM Tris, $500 \mathrm{mM} \mathrm{NaCl}$ at $\mathrm{pH} 7.5$ and $5 \%$ nonfat dry milk at $23^{\circ} \mathrm{C}$ with agitation. 
Membranes were then incubated overnight at 1:150 with a monoclonal antibody to 2,4-dinitrophenyl residues (part \#90451) that accompanied the OxyBlot Protein Oxidation Detection Kit purchased from Millipore. A standard membrane washing was performed in TBS containing $0.1 \%$ Tween-20 (TBST), 4 times, each time for 5 minutes at room temperature.

After washing with TBST, the membrane was incubated with the appropriate Horse Radish Peroxidase (HRP) conjugated secondary antibody against rabbit (1:300) (part \#90452 - OxyBlot Protein Oxidation Detection Kit, Millipore) for 1 hour. The membrane was then washed again in TBST and incubated with enhanced chemiluminescence detection reagent, from a SuperSignal West Pico Luminescent Kit (Thermo Fisher Scientific, Waltham, MA). HRP catalyses oxidation of luminal with peroxide, which then illuminated the tagged proteins. The image was captured with a Roper Scientific CCD camera that was then processed using the Alpha Innotech Fluorchem SP system (Quansys Biosciences, Logan, UT).

\subsection{Re-probing}

To establish loading controls and verification of ryanodine receptor band location and density, each PVDF membrane was re-probed for total RyR2. Before reprobing for RyR2, quenching of the goat, anti-rabbit secondary antibody that was attached to Rabbit Anti-DNPH antibody was accomplished by incubation of membranes in TBST with $3 \% \mathrm{w} / \mathrm{v}$ sodium azide $\left(\mathrm{NaN}_{3}\right)$ for a minimum of 3 hours. 
Sodium azide inhibits HRP activity of secondary antibodies and has been successfully used to quench the previous antibodies for re-probing with another antibody ${ }^{49}$. Membranes were then incubated overnight at a dilution of 1:7,000 with a mouse monoclonal antibody against RyR2 (C3-33, GeneTex), followed by washing and incubation for one hour at a dilution of 1:10,000 with a HRPconjugated secondary antibody against mouse (Santa Cruz Biotech) for 1 hour. After washing, the membrane was then incubated with enhanced chemiluminescence detection reagent and imaged.

\subsection{Western Blot Analysis}

Using the AlphaEaseFC software, an overlay of the Bio-Rad protein ladder and image produced from the anti-DNPH antibodies, as shown in figure 10, allowed for the relative mass and density of major bands that had been carbonylated to be determined. Once these bands had been identified spot density analysis was performed by drawing a box around the bands as well as a box used to subtract out the background as shown in figure 11. 

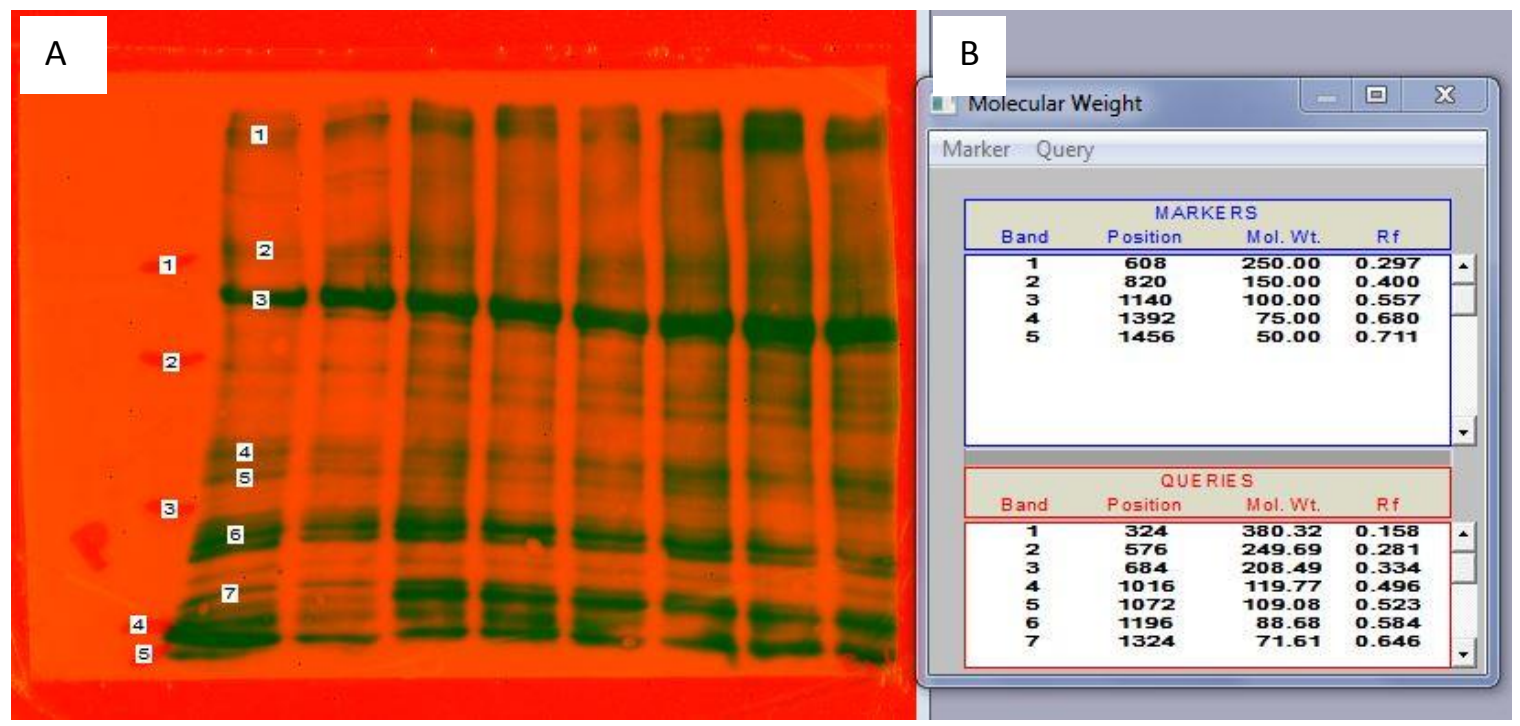

Figure 10: Determination of the molecular mass of significantly carbonylated bands. A) Overlay of the image obtained using white reflective light that shows the Bio-Rad protein ladder (dark red tint) and the image produced from HRP antibody using the chemiluminescence filter showing carbonylation (dark green tint). B) Calculations shown include band number which was assigned by the user, pixel position from the top of the image, user assigned molecular mass in the Markers window, and software calculated molecular mass in the queries window, and modified retention value (Rf) where $\mathrm{Rf}=1$ at the bottom of the gel and $\mathrm{Rf}=0$ at the top of the gel.
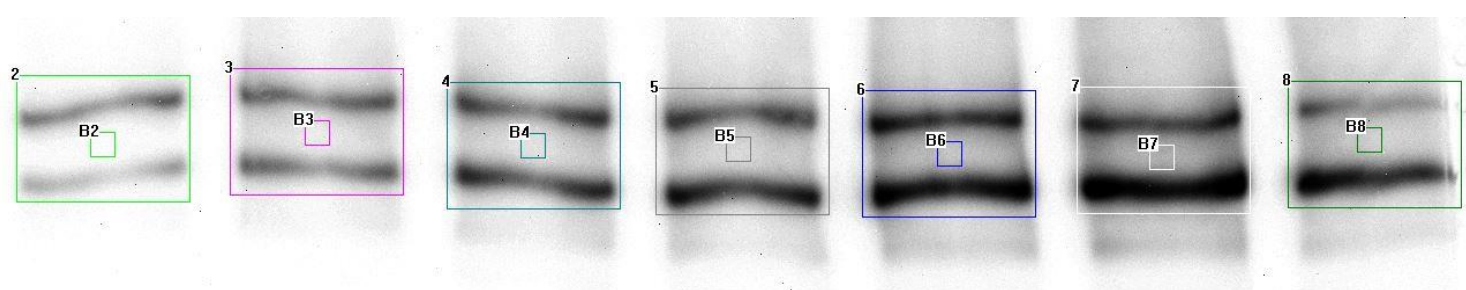

Figure 11: Spot density tool in the analysis tab found in the AlphaEaseFC software. 
The band density when imaged with the anti-DNPH antibodies was then standardized to the band density when imaged with the anti-RyR2 antibodies. This was done by dividing the integrated density values that had the background subtracted from the total carbonylation image, with the integrated density values that had the background subtracted from the total ryanodine receptor image. This value, carbonylation per ryanodine receptor, was then normalized to the control condition before being reported.

\subsection{Statistics}

Average data is shown as mean \pm standard error. Significance of the difference between control and test values from individual sets of experiments was calculated by a paired student's $t$ test. 


\section{Chapter 3: Results}

\subsection{The Cardiac Ryanodine Receptor is Sensitive to Homocysteine Thiolactone.}

Problems with intracellular $\mathrm{Ca}^{2+}$ cycling have been associated with heart failure, ischemic heart disease, and several genetic forms of arrhythmias. Our hypothesis, supported by the following results, is that treatment of SR with HTL results in carbonyl formation on RyR2 and as a result RyR2 is sensitized to activation by $\mathrm{Ca}^{2+}$. This is likely to result in spontaneous cardiac arrhythmias and heart failure. This observation provides the first link between elevated homocysteine levels in humans and alteration to sarcoplasmic reticulum function. As shown in Figure 12, and summarized in Figure 13 and Table 1, increasing levels of Homocysteine Thiolactone decreases the amount of calcium needed for activation of Ryanodine Binding. At 100nM, a physiologically relevant concentration, $\mathrm{HTL}$ shifts $\mathrm{Ca}^{2+}$ dependent ryanodine binding in cardiac muscle SR from a $k_{d}$ of $129.7 \pm 3.4$ to a $k_{d}$ of $102.0 \pm 2.7$ when the solution redox potential has been set to $-210 \mathrm{mV}$ at $\mathrm{pH} 7.4$. This change in $\mathrm{Ca}^{2+}$ dependent activation was consistently observed in multiple cardiac SR preparations derived from multiple hearts. 


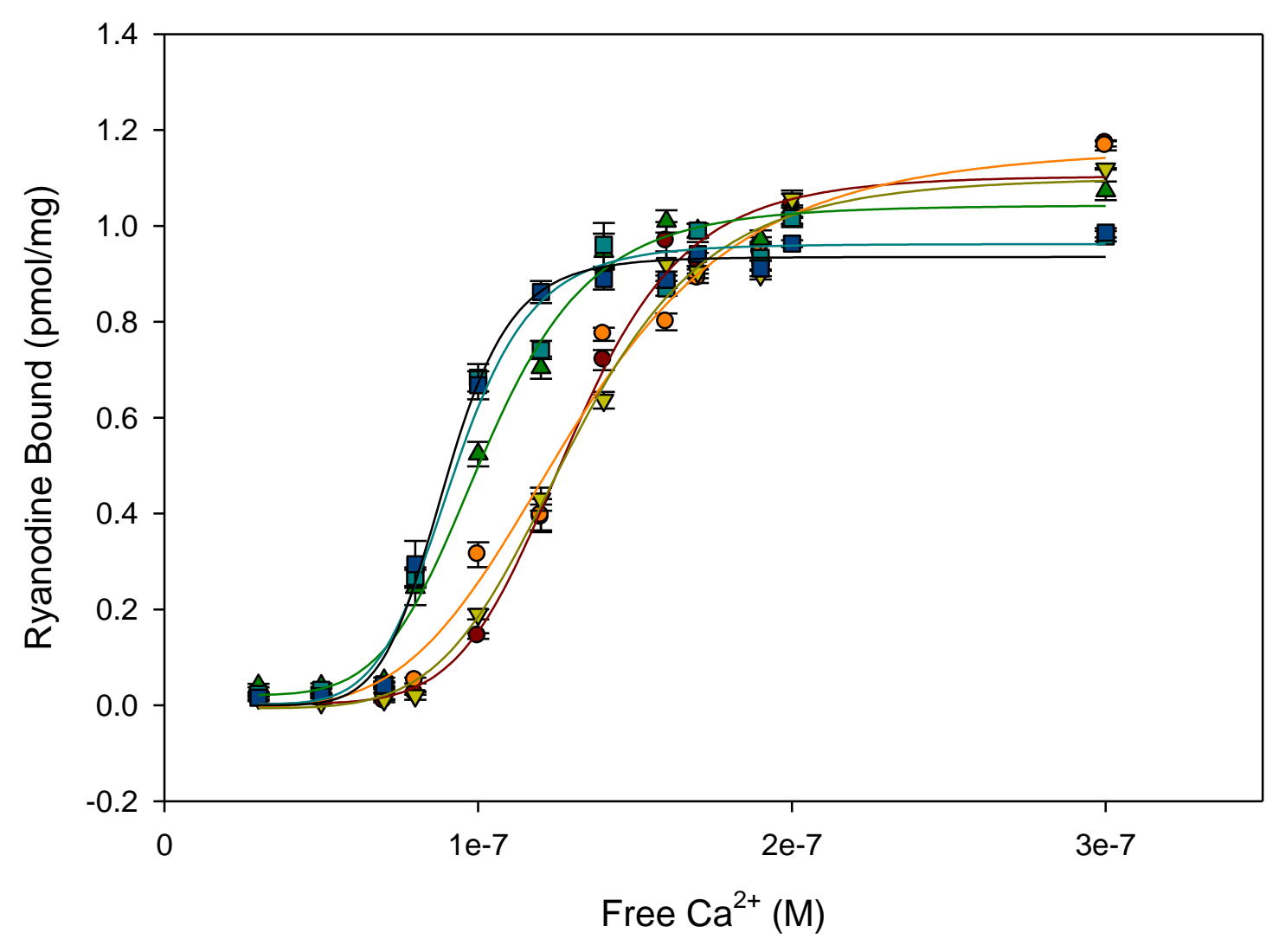

Figure 12: $\mathrm{HTL}$ sensitizes RyR2 to $\mathrm{Ca}^{2+}$ dependent activation. Control cardiac

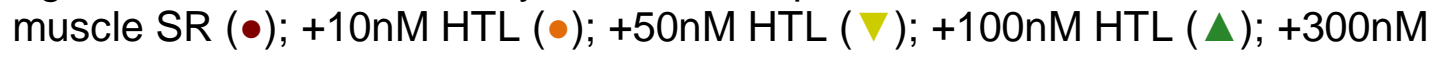
HTL (घ); +500nM HTL (匹) Ryanodine binding assay was carried out over a period of 3 hours at $\mathrm{pH} 7.4,37^{\circ} \mathrm{C}$, a redox potential of $-210 \mathrm{mV}$ and final protein concentration of $0.5 \mathrm{mg} / \mathrm{ml}$. Buffer contained $250 \mathrm{mM} \mathrm{KCl}, 15 \mathrm{mM} \mathrm{NaCl}$, and $20 \mathrm{mM}$

PIPES with various $\mathrm{EGTA} / \mathrm{CaCl}_{2}$ concentrations calculated to result in various free $\mathrm{Ca}^{2+}$ values that were later verified with the calcium electrode. The binding reaction was quenched by rapid filtration through Whatman glass fiber filters using a Brandel cell harvester. Filters were washed twice with approximately $4 \mathrm{ml}$ of buffer containing $250 \mathrm{mM} \mathrm{KCl}, 15 \mathrm{mM} \mathrm{NaCl}, 20 \mathrm{mM}$ TRIS, and $100 \mu \mathrm{M} \mathrm{CaCl}_{2}$ at $\mathrm{pH} 7.1(\mathrm{HCl})$. These filters were then dried in an oven at $50^{\circ} \mathrm{C}$ for two hours, then incubated with agitation in $3 \mathrm{ml}$ of CytoScint scintillation fluid for one hour. Radioactivity was counted by a Beckman LS 6000 scintillation counter with an efficiency of approximately $55 \%$. Data shown as average \pm standard error with $\mathrm{n}=6$. Data was fit using a four parameter Hill curve (equation 5). 


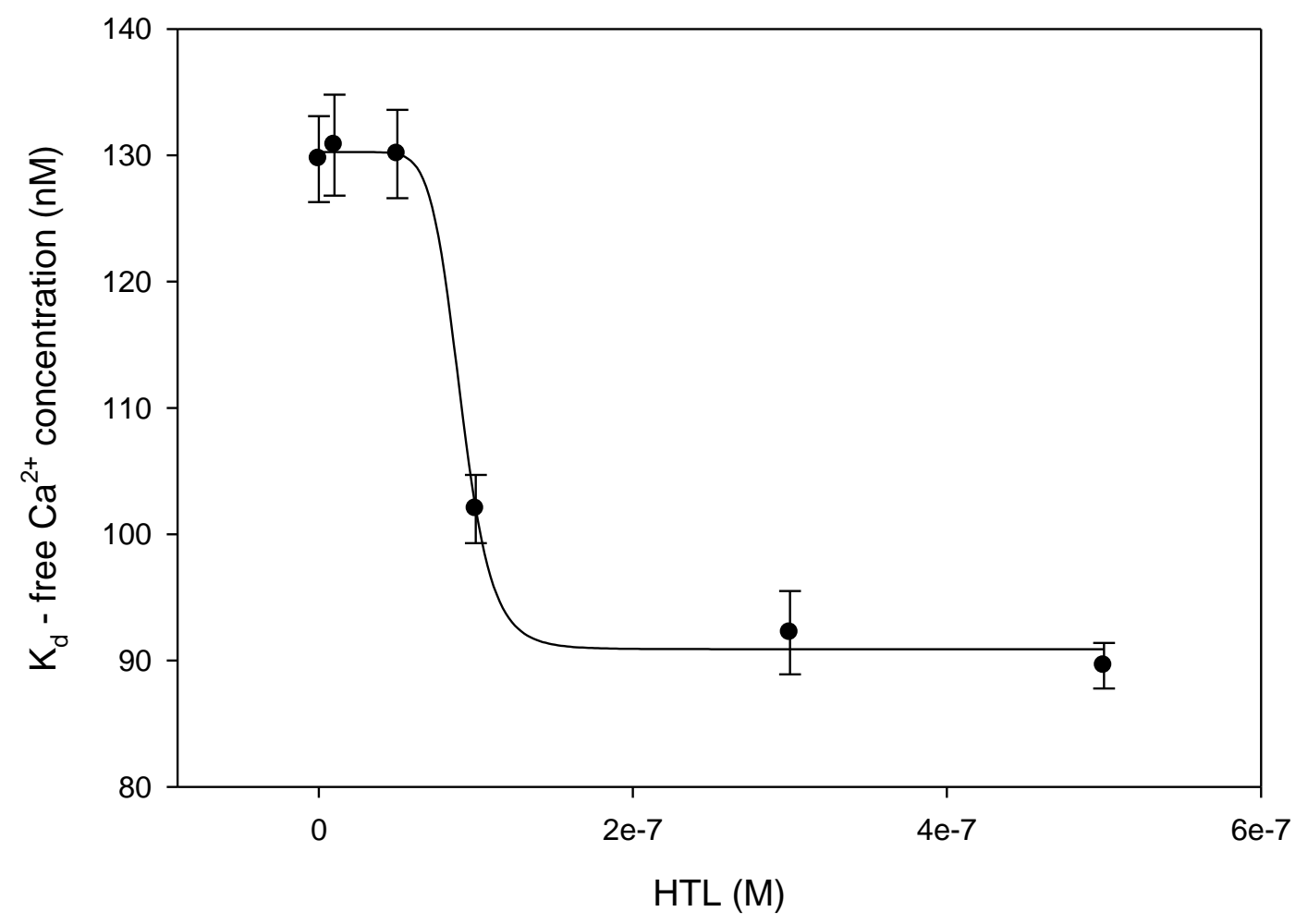

Figure 13: Shift in $\mathrm{Ca}^{2+}$ concentration needed to half maximally activate ryanodine binding in cardiac muscle as a function of HTL concentration. Data shown is derived from Figure 12. The data was fit to equation 7 , the four parameter logistic curve resulting in an $\mathrm{EC}_{50}$ of $90.4 \pm 15.5 \mathrm{nM}$.

\begin{tabular}{|c|c|c|c|c|c|c|}
\hline$[\mathrm{HTL}]$ & Control & $10 \mathrm{nM}$ & $50 \mathrm{nM}$ & $100 \mathrm{nM}$ & $300 \mathrm{nM}$ & $500 \mathrm{nM}$ \\
\hline $\mathrm{Kd} \mathrm{Ca}^{2+}$ & $129.7 \pm 3$. & $130.8 \pm 4$. & $130.1 \pm 3$. & $102.0 \pm 2$. & $92.2 \pm 3$. & $89.6 \pm 1$. \\
$(\mathrm{nM})$ & 4 & 0 & 5 & 7 & 3 & 8 \\
\hline $\begin{array}{c}\text { Hill } \\
\text { Numbe } \\
\mathrm{r}\end{array}$ & $7.0 \pm 1.0$ & $4.6 \pm 0.7$ & $5.9 \pm 0.8$ & $6.0 \pm 0.8$ & $7.3 \pm 1.5$ & $8.5 \pm 1.1$ \\
\hline
\end{tabular}

Table 1: Comparison of $\mathrm{Kd}_{d} \mathrm{Ca}^{2+}$ values and Hill numbers for different HTL concentrations. 


\subsection{The adduct formed between Homocysteine Thiolactone and excess Glutathione does not cause functional changes to RyR2.}

Previous studies have shown that HTL reacts with a range of free amino acids and reducing agents ${ }^{31}$. What is known, comes from kinetic studies that follow these reaction using UV absorption. These studies were carried out by monitoring the absorbance of $100 \mu \mathrm{M} \mathrm{HTL}$ at $240 \mathrm{~nm}$ in a $100 \mathrm{mM}$ HEPES buffer at $\mathrm{pH} 7.4$ and $37^{\circ} \mathrm{C}$ with each amino acid at a concentration of $1.25 \mathrm{mM}$. It was reported that the HTL-lysine reaction has a half-life of 3 hours as opposed to 8.5 hours when incubated with Glutathione or the control half-life of 25 hours.

To determine if the large excess of GSH ( 2mM) present in our experiments (and in the cell environment) results in the formation of an HTL-GSH adduct which then reacts with and causes functional changes to the RyR2, the following experiment was performed: Two concentrations of HTL, (200nM \& $600 \mathrm{nM}$ ) were incubated at $37^{\circ} \mathrm{C}$, with $4 \mathrm{mM} \mathrm{GSH}$ in ryanodine binding buffer for 24 hours. A solution of $\mathrm{SR}$ and ${ }^{3} \mathrm{H}$-Ryanodine was then added to both these solutions, at various free $\mathrm{Ca}^{2+}$ concentrations for an additional 3 hours. As shown in Figure 14, and summarized in Table 2, there was no change to the concentration of free $\mathrm{Ca}^{2+}$ needed to half maximally activate ryanodine binding when GSH is pre-incubated at different concentrations of HTL, and control conditions in the absence of HTL. 


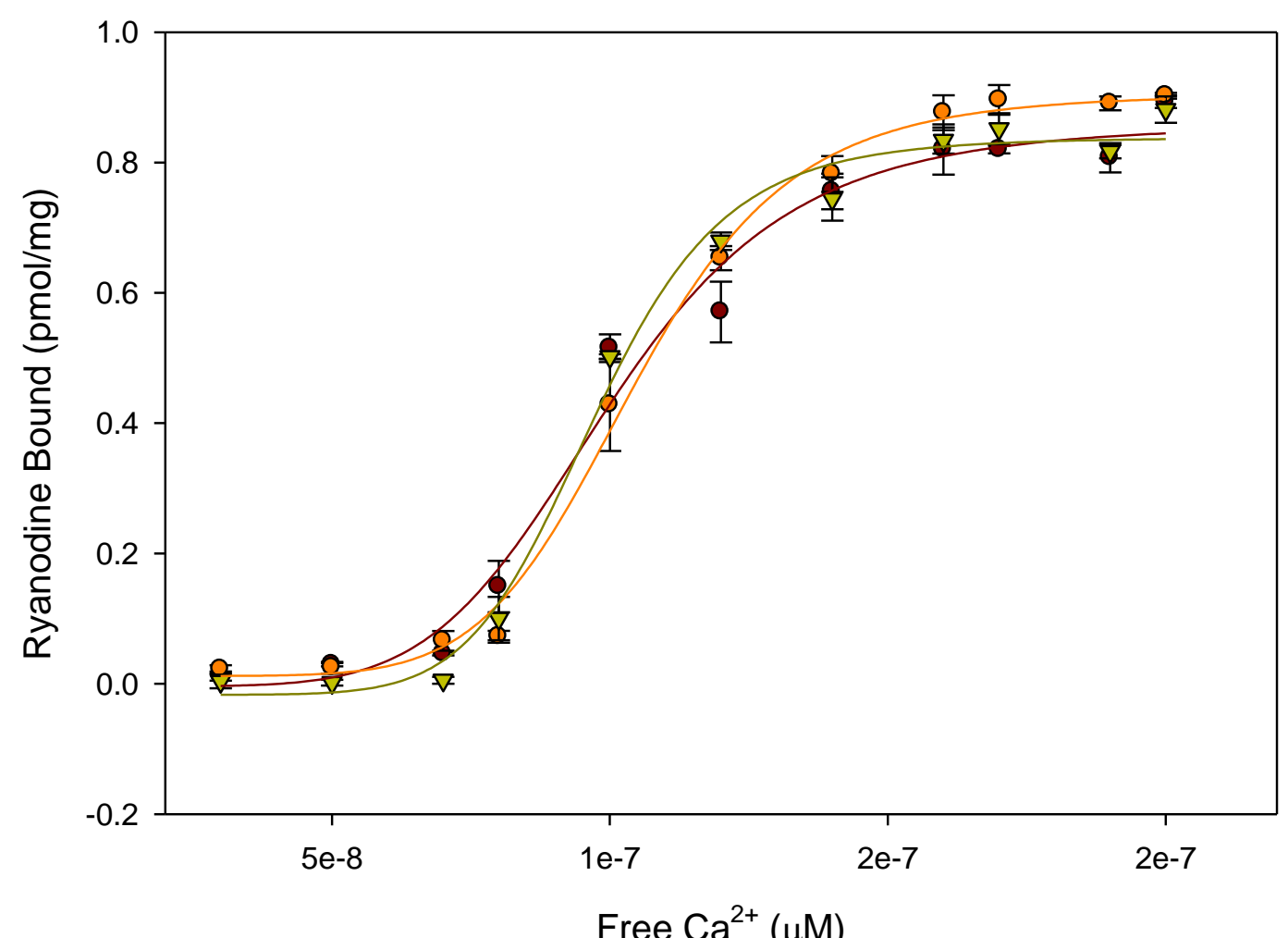

Figure 14: HTL and GSH adducts formed after 24 hours do not change the sensitivity of RyR2. Control Cardiac SR $(\bullet),+100 \mathrm{nM} \mathrm{HTL}(\bullet),+300 \mathrm{nM} \mathrm{HTL}(\nabla)$. $4 \mathrm{mM}$ GSH and various concentrations of $\mathrm{HTL}$ were incubated in ryanodine binding buffer for twenty four hours before being used in the ryanodine binding assay that was carried out over a period of 3 hours at $\mathrm{pH} 7.4,37^{\circ} \mathrm{C}$, and a final protein concentration of $0.5 \mathrm{mg} / \mathrm{ml}$. Data shown as average \pm standard error with $\mathrm{n}=6$. Data was fit using a four parameter Hill curve (equation 5).

\begin{tabular}{|c|c|c|c|}
\hline$[\mathrm{HTL}]$ & Control & $100 \mathrm{nM}$ & $300 \mathrm{nM}$ \\
\hline $\mathrm{K}_{\mathrm{d}} \mathrm{Ca}^{2+}(\mathrm{nM})$ & $99.8 \pm 4.2$ & $104.5 \pm 3.7$ & $97.4 \pm 3.2$ \\
\hline Hill number & $6.0 \pm 1.2$ & $7.3 \pm 0.8$ & $7.9 \pm 1.3$ \\
\hline
\end{tabular}

Table 2: Comparison of $\mathrm{Kd} \mathrm{Ca}^{2+}$ values for different concentrations of HTL. 


\subsection{Functional changes on RyR2 by Homocysteine Thiolactone are redox} sensitive.

The effect of $100 \mathrm{nM} \mathrm{HTL}$ sensitizing the RyR2 to activation by $\mathrm{Ca}^{2+}$ was observed to a greater extent with a reducing solution potential than in an oxidizing one. At a solution redox potential of $-210 \mathrm{mV}$, the $\mathrm{Kd}_{\mathrm{d}}$ of the $\mathrm{Ca}^{2+}$ dependent curve with $100 \mathrm{nM} \mathrm{HTL}$ is $49.2 \pm 4.1 \mathrm{nM}$ further to the left than the control condition. At solution redox potential of $-100 \mathrm{mV}$, the $\mathrm{K}_{d}$ of the $\mathrm{Ca}^{2+}$ dependent curve with $100 \mathrm{nM} \mathrm{HTL}$ is only $36.4 \pm 4.6 \mathrm{nM}$ further to the left than the control condition.

Another item of note is that the maximal binding of ryanodine is less at the $-100 \mathrm{mV}$ redox solution potential than the $-210 \mathrm{mV}$ solution redox potential. This is an artifact due to the high sensitivity of ryanodine binding to salt concentration in the sample buffer. In order to achieve a solution redox potential of $-100 \mathrm{mV}$, almost half of the total sample volume must be the oxidized glutathione stock solution. This results in a decrease in the salt concentration and a decrease in ryanodine binding. 


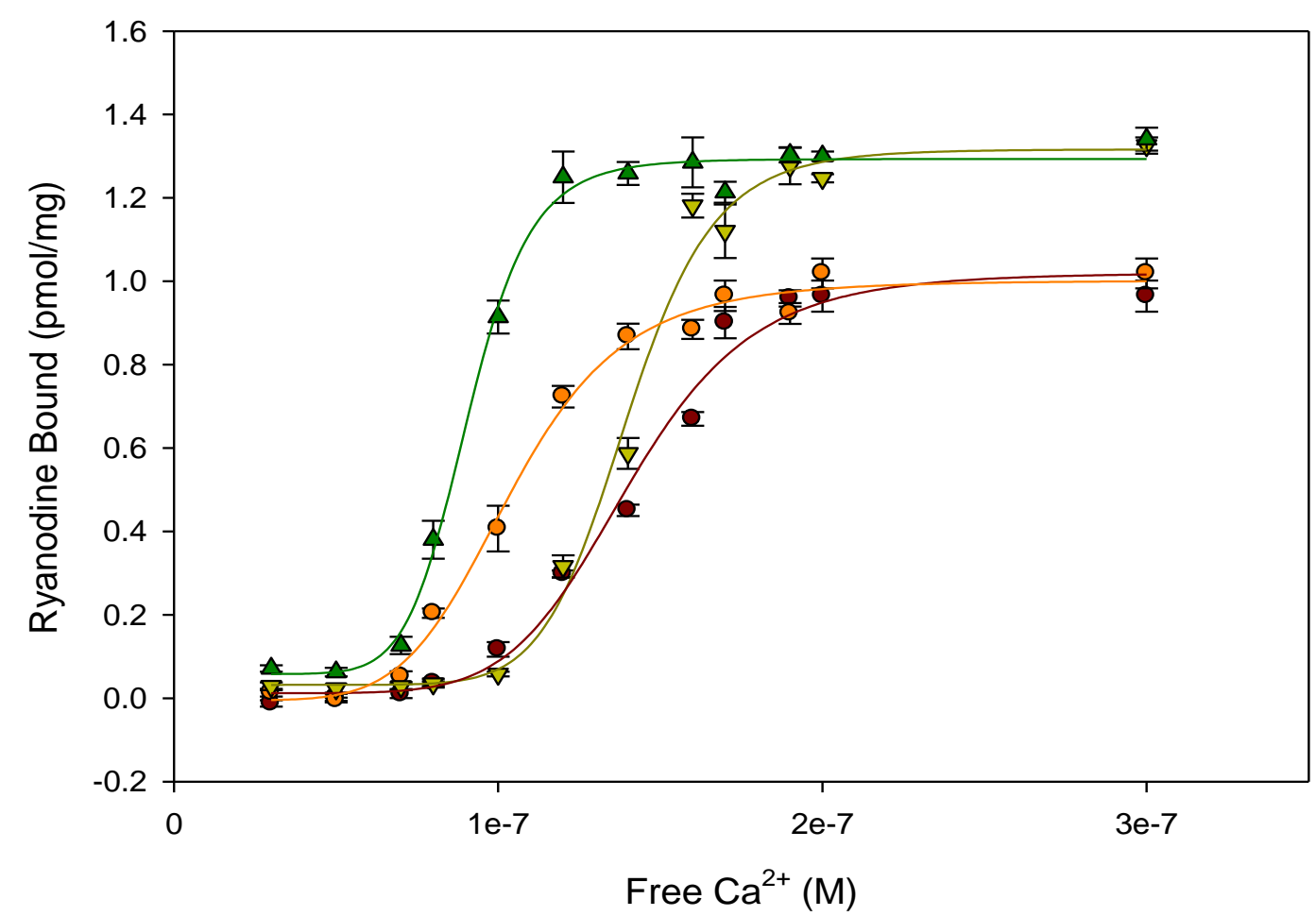

Figure 15: Solution redox potential alters the ability of HTL to sensitize RyR2 to $\mathrm{Ca}^{2+}$ dependent activation. Control Cardiac SR set at $-100 \mathrm{mV}(\bullet),+100 \mathrm{nM}$ HTL set at $-100 \mathrm{mV}(\bullet)$, Control Cardiac SR set at $-210 \mathrm{mV}(\nabla),+100 \mathrm{nM} \mathrm{HTL}$ set at $210 \mathrm{mV}(\boldsymbol{\Delta})$. GSH/GSSG concentrations were incubated with the SR for one hour before various concentrations of $\mathrm{HTL}$ and ${ }^{3} \mathrm{H}$-Ryanodine were added to start the ryanodine binding assay that was then carried out over a period of 3 hours at $\mathrm{pH}$ $7.4,37^{\circ} \mathrm{C}$, and a final protein concentration of $0.5 \mathrm{mg} / \mathrm{ml}$. Data shown as average \pm standard error with $n=6$. Data was fit using a four parameter Hill curve (equation 5).

\begin{tabular}{|c|c|c|c|c|c|}
\hline $\begin{array}{c}\text { Redox } \\
\text { Potential }\end{array}$ & $\begin{array}{c}\mathrm{K}_{d} \mathrm{Ca}^{2+} \\
(\text { Control) }\end{array}$ & $\begin{array}{c}\text { Hill } \\
\text { number }\end{array}$ & $\begin{array}{c}\mathrm{Kd} \mathrm{Ca}^{2+} \\
100 \mathrm{nM} \mathrm{HTL} \\
(\mathrm{nM})\end{array}$ & $\begin{array}{c}\text { Hill } \\
\text { number }\end{array}$ & $\begin{array}{c}\text { Total shift } \\
\text { in } \mathrm{K}_{d} \\
(\mathrm{nM})\end{array}$ \\
\hline No GSH/ GSSG & $133.3 \pm 4.3$ & $5.3 \pm 0.8$ & $102.4 \pm 4.8$ & $5.7 \pm 1.3$ & $30.9 \pm 6.4$ \\
\hline$-100 \mathrm{mV}$ & $140.7 \pm 3.8$ & $9.3 \pm 1.4$ & $104.3 \pm 1.8$ & $7.0 \pm 0.6$ & $36.4 \pm 4.6$ \\
\hline$-150 \mathrm{mV}$ & $136.0 \pm 1.7$ & $9.8 \pm 1.0$ & $98.5 \pm 1.3$ & $8.2 \pm 0.7$ & $37.5 \pm 4.2$ \\
\hline$-210 \mathrm{mV}$ & $139.9 \pm 2.5$ & $10.4 \pm 1.6$ & $90.7 \pm 3.2$ & $9.3 \pm 0.9$ & $49.2 \pm 4.1$ \\
\hline
\end{tabular}

Table 3: Shift in $\mathrm{Ca}^{2+}$ dependent ryanodine binding $\mathrm{k}_{\mathrm{d}}$, as a function of redox potential and HTL concentration 


\subsection{Homocysteine Thiolactone causes a functional change in RyR2 in a time} dependent manner.

As shown in Figure 16, and summarized in Table 4, the longer the incubation period, the further the HTL can shift the $\mathrm{Ca}^{2+}$ dependent activation curve. With a 2 hour incubation containing $100 \mathrm{nM} \mathrm{HTL}, 0.5 \mathrm{mg} / \mathrm{ml} \mathrm{SR},{ }^{3} \mathrm{H}-$ Ryanodine at various free $\mathrm{Ca}^{2+}$ concentrations, the average $\mathrm{K}_{d}$ was only changed by $9.4 \pm 11.6 \mathrm{nM}$. When the HTL and ${ }^{3} \mathrm{H}$-Ryanodine had been incubated with the SR for 4 hours, the average $K_{d}$ was reduced by $25 \pm 7.1 \mathrm{nM}$, and with a 6 hour incubation the average $K_{d}$ was reduced by $28 \pm 5.2 n M$. However, the error bars on the values determined from the two hour incubation condition are large. This is possibly due to ryanodine binding not yet having researched equilibrium after 2 hours of incubation, and or HTL not yet having completed the reaction with the ryanodine receptor. 


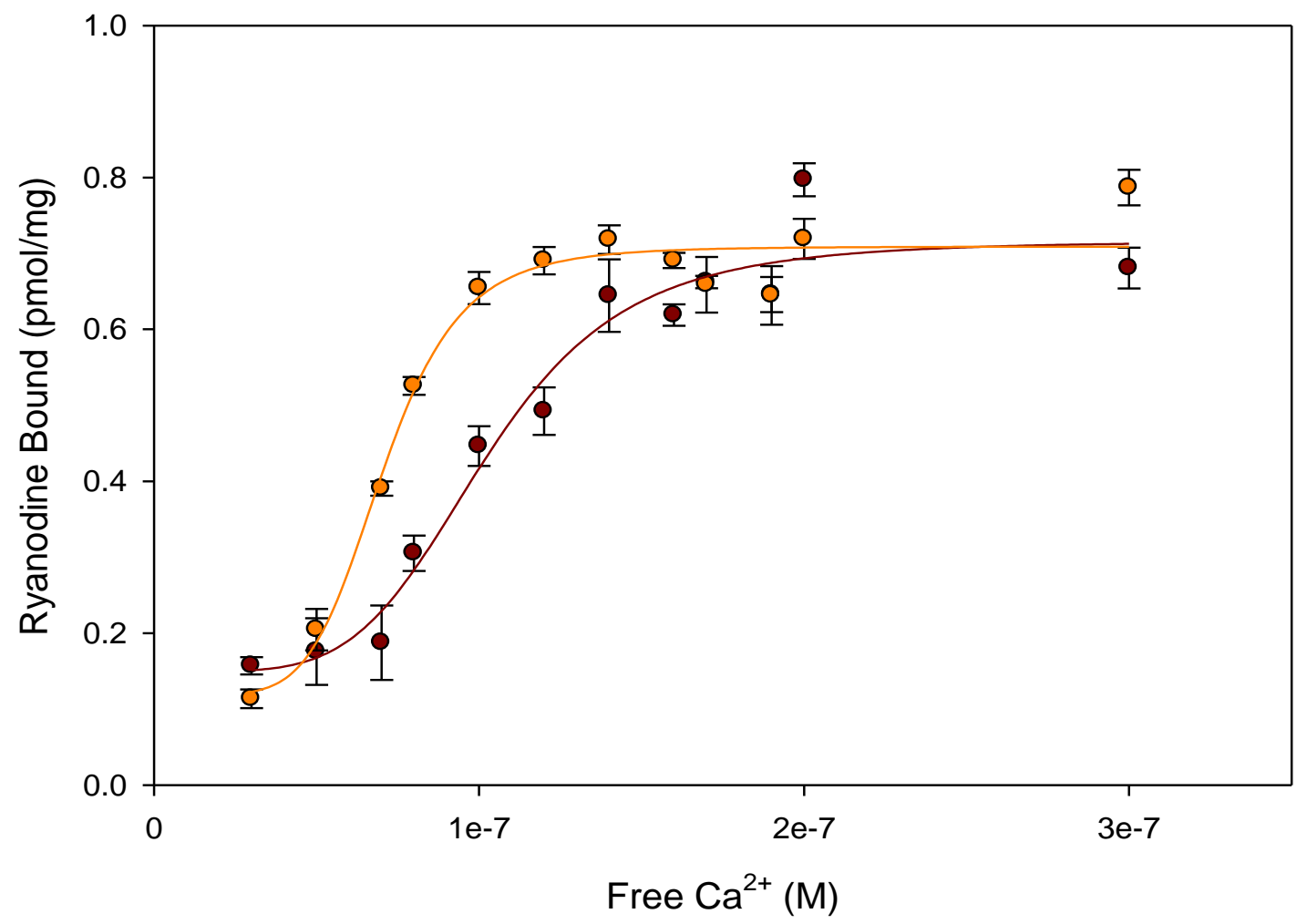

Figure 16: Shift in $\mathrm{Ca}^{2+}$ dependent ryanodine binding after 6 hours of incubation with or without 100nM HTL. Control Cardiac SR $(\bullet),+100$ nM HTL $(\bullet)$. The ryanodine binding assay that was carried out over a period of 6 hours. During the 6 hours, ${ }^{3} \mathrm{H}$-ryanodine with or without $\mathrm{HTL}$, at $\mathrm{pH} 7.4,37^{\circ} \mathrm{C},-210 \mathrm{mV}$ redox potential and a final protein concentration of $0.5 \mathrm{mg} / \mathrm{ml}$ were incubated at various free $\mathrm{Ca}^{2+}$ concentrations. Data shown as average \pm standard error with $\mathrm{n}=6$. Data was fit using a four parameter Hill curve (equation 5).

\begin{tabular}{|l|l|l|l|l|l|l|}
\hline & 2 hours & $\begin{array}{l}\text { Hill } \\
\text { number }\end{array}$ & 4 hours & $\begin{array}{l}\text { Hill } \\
\text { number }\end{array}$ & 6 hours & $\begin{array}{l}\text { Hill } \\
\text { number }\end{array}$ \\
\hline $\begin{array}{l}\mathrm{K}_{\mathrm{d}} \mathrm{Ca}^{2+}- \\
\text { Control }\end{array}$ & $105.4 \pm 8.6$ & $4.3 \pm 1.0$ & $110.0 \pm 5.2$ & $4.0 \pm 0.7$ & $108.2 \pm 3.0$ & $4.8 \pm 1.3$ \\
\hline $\begin{array}{l}\mathrm{K}_{\mathrm{d}} \mathrm{Ca}^{2+-} \\
100 \mathrm{nM} \\
\mathrm{HTL}\end{array}$ & $95.6 \pm 7.9$ & $3.4 \pm 1.5$ & $85.3 \pm 4.9$ & $5.5 \pm 1.5$ & $80.5 \pm 4.3$ & $5.9 \pm 1.5$ \\
\hline
\end{tabular}

Table 4: Shift in $\mathrm{Ca}^{2+}$ dependent ryanodine binding $\mathrm{K}_{\mathrm{d}}$, as a function of time and HTL concentration. 


\subsection{Homocysteine Thiolactone causes carbonylation of RyR2 in a}

\section{concentration dependent manner.}

Formation of carbonyl functional groups was quantified by addition 2,4-

dinitrophenylhydrazine (DNPH) to form 2,4-dinitrophenylhydrozone (DNPH-

hydrazone). Formation of carbonyls on the RyR2 can be followed specifically by

first separating the SR proteins by polyacrylamide gel electrophoresis followed by

Western Blot transfer, and quantified using antibodies to DNPH-hydrazone by

ECL. A representative western blot image showing an increase in carbonyl signal as a function of $\mathrm{HTL}$ is shown in figure 17.

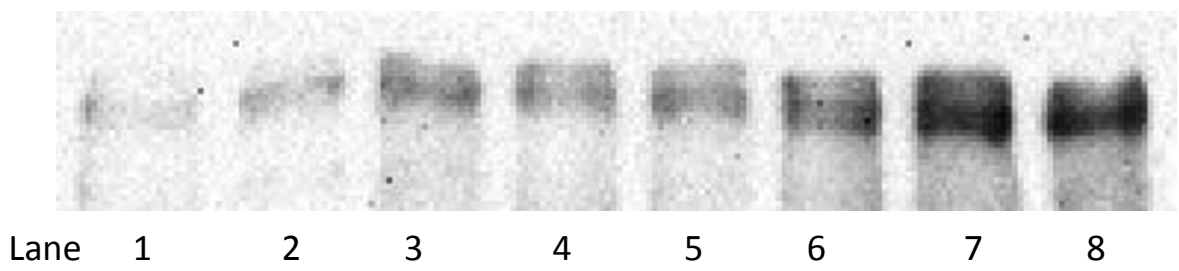

Figure 17: Western blot image of RyR2 treated with increasing concentrations of HTL showing increased carbonylation. Protocol is described in the caption to figure 18 .

Lane 1: Control

Lane 2: 10nM HTL

Lane 3: 30nM HTL
Lane 4: 100nM HTL

Lane 5: 200nM HTL

Lane 6: 300nM HTL
Lane 7: 700nM HTL

Lane 8: $1 \mu \mathrm{M} \mathrm{HTL}$ 
Each blot was analyzed to determine carbonylation of RyR2. It was then reprobed for total RyR2 for standardization, followed by normalization to the control condition. This was done by dividing the integrated density values that had the background subtracted from the total carbonylation image, with the integrated density values that had the background subtracted from the total ryanodine receptor image. This value, carbonylation per ryanodine receptor, was then normalized to the control condition before being collated with multiple trials and summarized in Figure 18. 


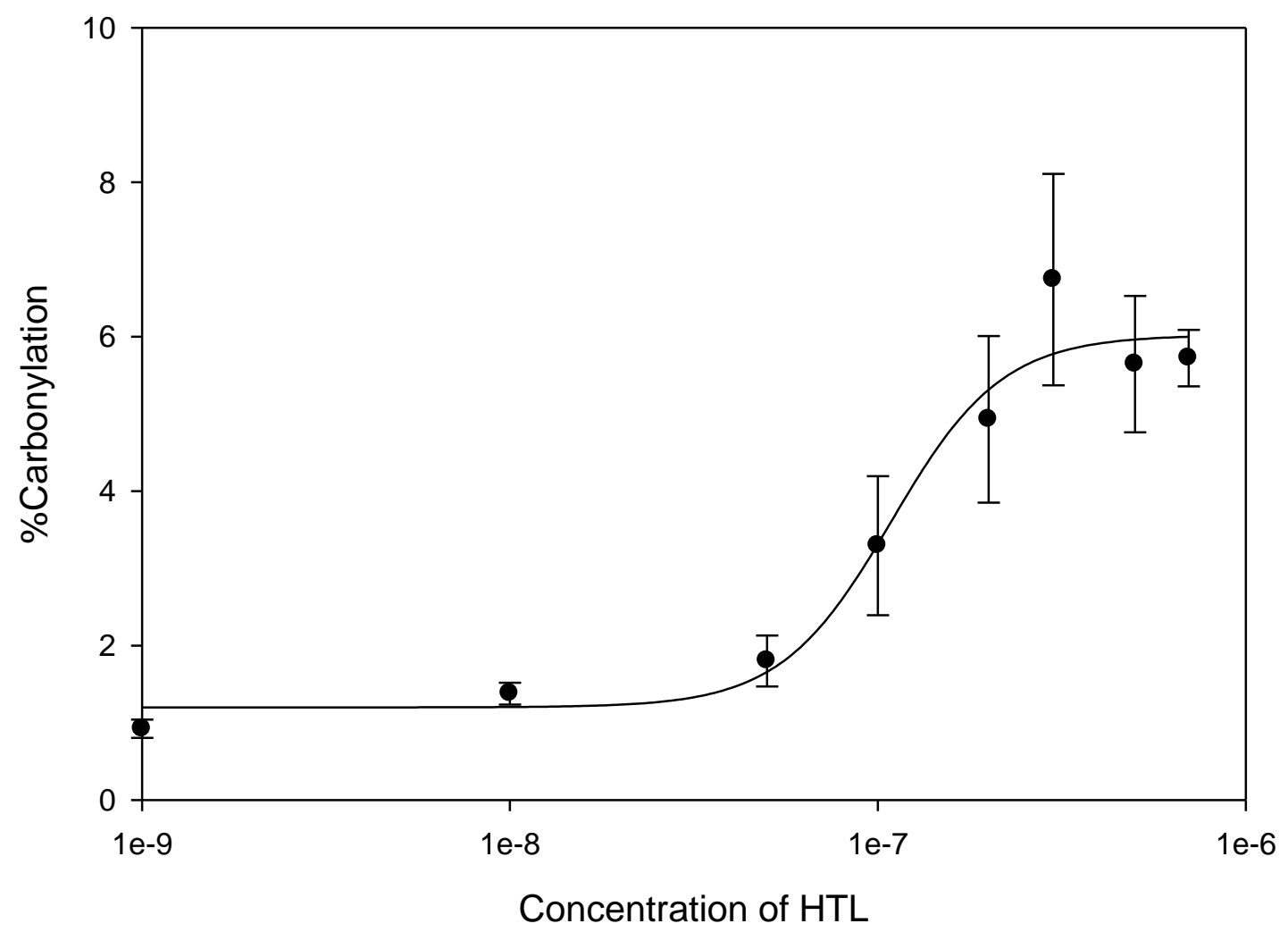

Figure 18: Carbonylation of RyR2 as a function of HTL concentration. RyR2 from sheep cardiac SR were incubated with various concentrations of HTL for 14-16 hours in a solution at a redox potential of $-210 \mathrm{mV}(2 \mathrm{mM}$ GSH \& $238 \mu \mathrm{M} \mathrm{GSSG})$, $37^{\circ} \mathrm{C}$ and $300 \mathrm{nM}$ free $\mathrm{Ca}^{2+}\left(30 \mu \mathrm{M} \mathrm{CaCl}_{2} \& 35.3 \mu \mathrm{M} \mathrm{EGTA}\right)$ in ryanodine binding buffer $(250 \mathrm{mM} \mathrm{KCl}, 15 \mathrm{mM} \mathrm{NaCl}, 20 \mathrm{mM}$ PIPES pH 7.4) before the reaction was stopped with a series of washes with nano-pure water. Protein was then probed for carbonylation using $10 \mathrm{mM}$ DNPH followed by neutralization (2M TRIS/30\% Glycerol) and solubilized with $8 \%(\mathrm{w} / \mathrm{v})$ SDS and $3 \% \beta$-mercaptoethanol. $15 \mu \mathrm{g}$ of protein per lane were then run on a 3-8\% SDS-PAGE gel followed by a 16 hour transfer onto PVDF membrane at $15 \mathrm{~V}$ at $4{ }^{\circ} \mathrm{C}$. Monitoring of carbonylation was done using anti-DNPH residue antibodies (1:150) and standardization was done using anti-RyR2 antibody (C3-33 at 1:7,000). Three experiments, each with a different cardiac SR prep, generated 2 PVDF membranes that were imaged and analyzed and this value, carbonylation per ryanodine receptor, was then normalized to the control condition before being averaged and reported \pm standard error. The data was fit to equation 7 , the four parameter logistic curve resulting in an $\mathrm{EC}_{50}$ of $108.8 \pm 20.3 \mathrm{nM}$. 


\subsection{Reducing redox potential enhances Homocysteine Thiolactone}

\section{carbonylation on RyR2}

We have shown in Figure 15 that at a more negative redox potential, the shift in the $\mathrm{Ca}^{2+}$ dependence is larger. In Figure 19 we delve into the question of whether or not carbonylation of the protein is correlated with the redox potential.

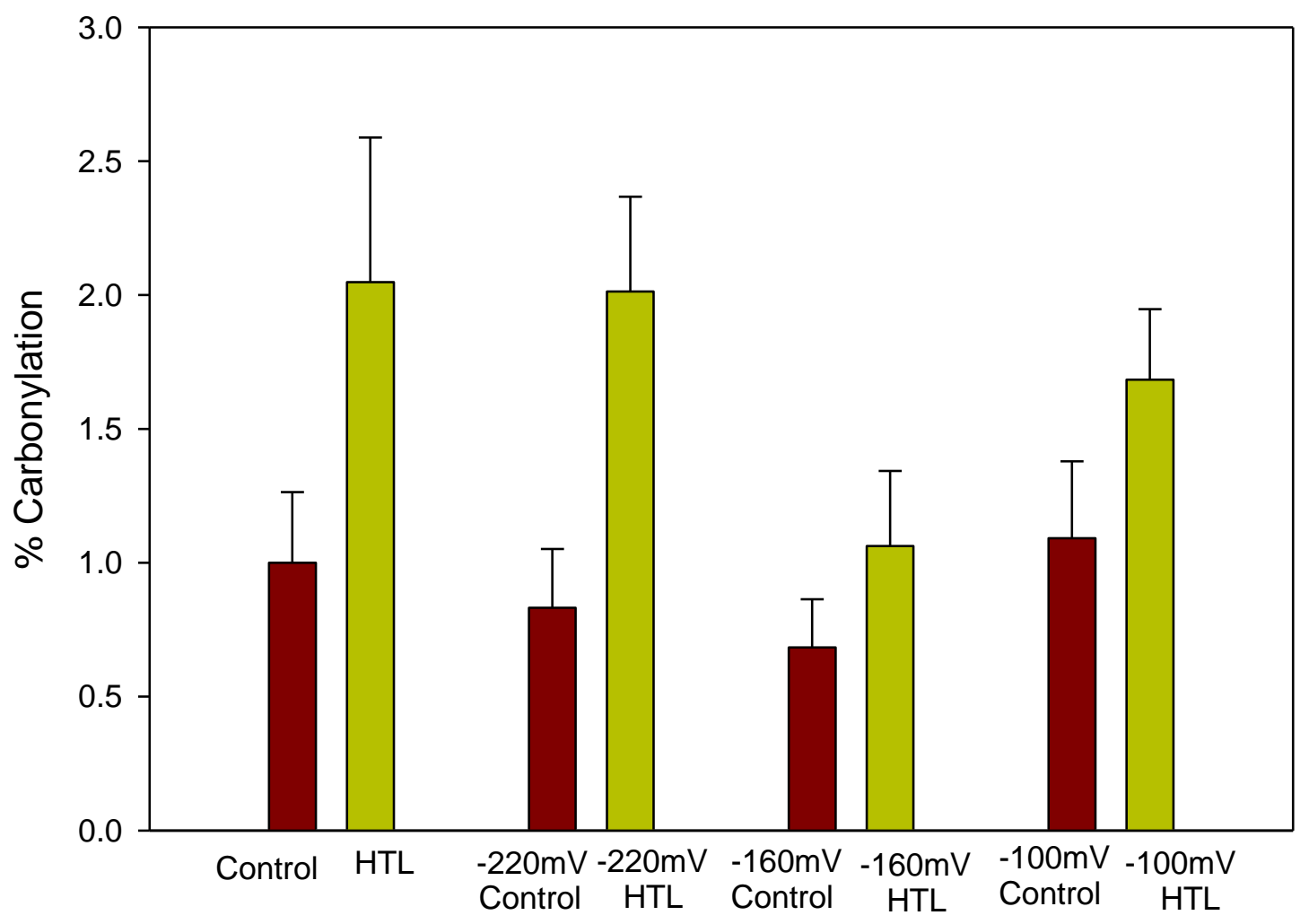

Figure 19: Carbonylation as a function of solution redox potential with or without 100nM HTL. RyR2 from sheep cardiac SR were incubated at various solution redox potentials with and without $100 \mathrm{nM} \mathrm{HTL}$ for $14-16$ hours at $37^{\circ} \mathrm{C}$ before the reaction was stopped with a series of washes. Percent carbonylation was then determined as described previously. One experiment, generating 4 PVDF membranes that were imaged and analyzed and this value, carbonylation per ryanodine receptor, was then normalized to the control condition before being averaged and reported \pm standard error. 


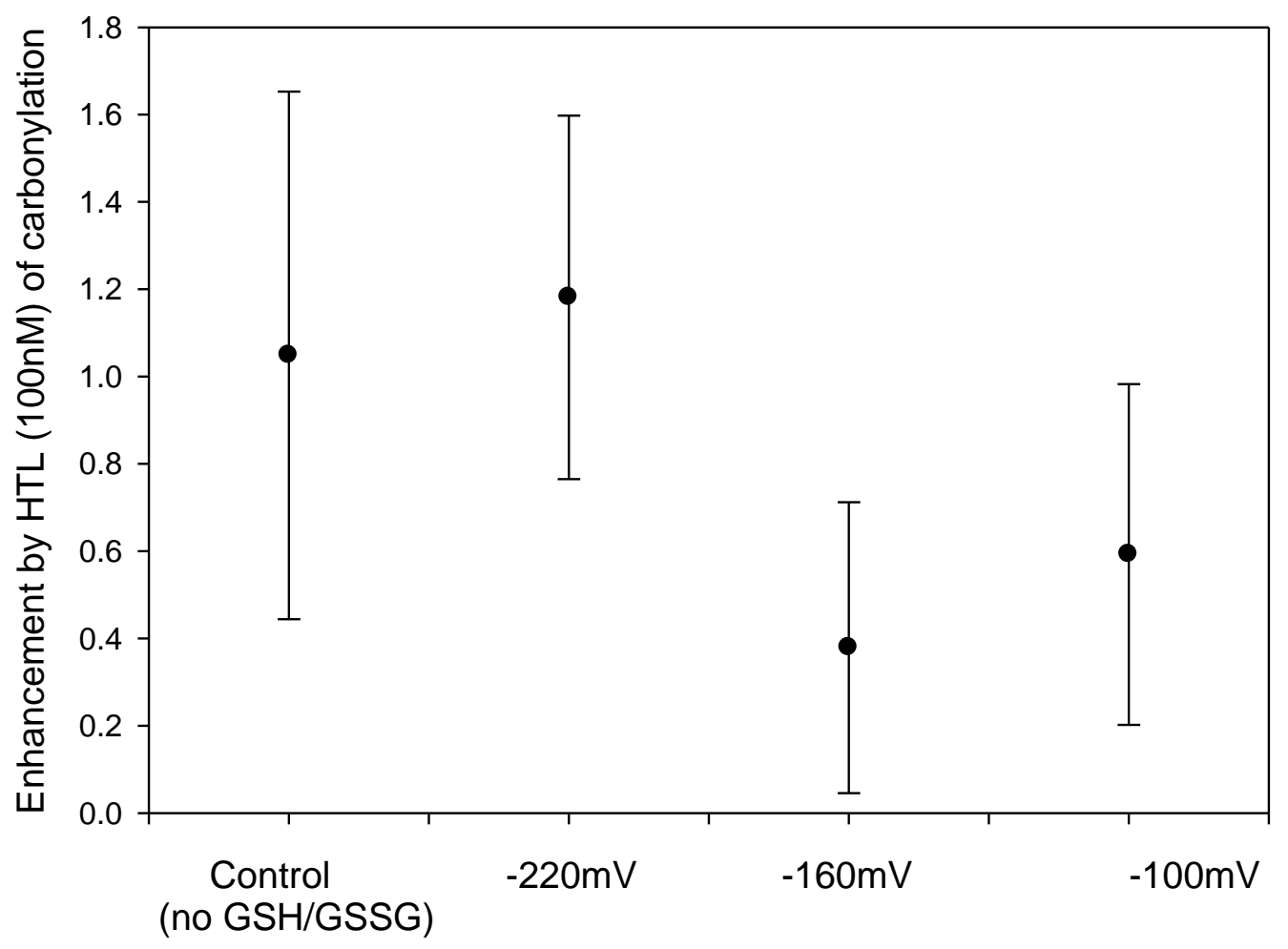

Figure 20: Enhancement of carbonylation by HTL as a function of solution redox potential. Data shown is derived from Figure 19 by taking the difference between the average amount of carbonylation with or without HTL. Error is propagated by taking the square root of the sum of the square error values. There is no statically significant difference between any of these determination. 


\subsection{Carbonylation on RyR2 increases as a function of time, with or without} HTL

As shown in Figure 21, carbonylation increases as a function of time with or without HTL. This figure also illustrates that either natively or due to sample handling the Ryanodine Receptor has carbonyl groups present. The reason for measuring carbonyls before solublization is to measure carbonyl formation in the native (non-denatured) state. Quantifying the signal was also easier when measuring carbonyls before solublization due to the high number of carbonyls exposed after solublization that created a large background signal. While under the control conditions carbonyl formation appears to reach saturation after four hours. HTL dependent carbonyl formation appears to increase at 6 hours. 
Time of carbonylation formation

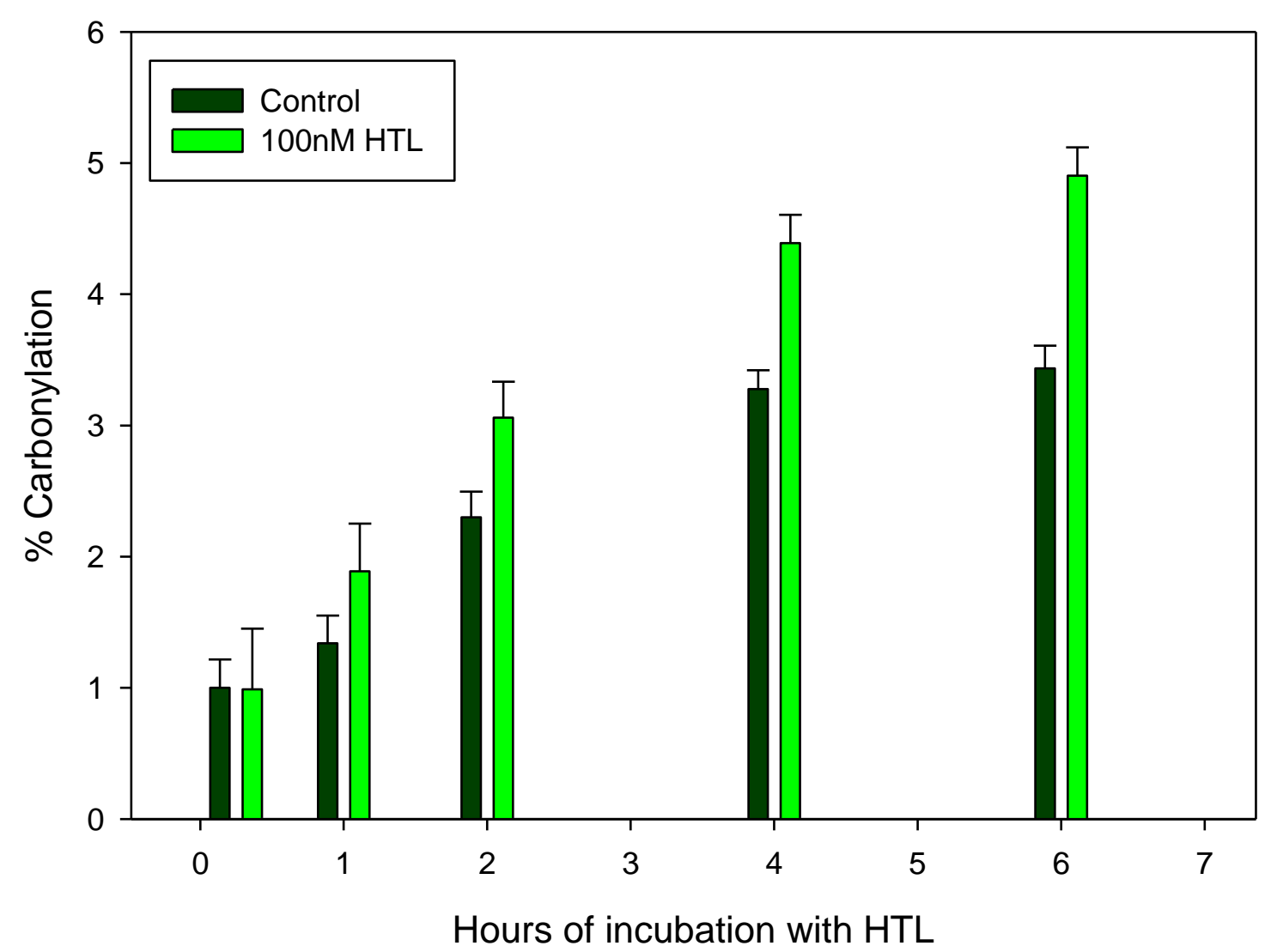

Figure 21: Carbonylation increases as a function of time and HTL. Sheep cardiac SR vesicles were incubated with or without $100 \mathrm{nM} \mathrm{HTL}$ for various amounts of time in ryanodine binding buffer at a solution redox potential of $-210 \mathrm{mV}$ and $37^{\circ} \mathrm{C}$ before the reaction was stopped at one time with a series of washes. One experiment, generating 4 PVDF membranes that were imaged and analyzed and this value, carbonylation per ryanodine receptor, was then normalized to the control condition before being averaged and reported \pm standard error. 


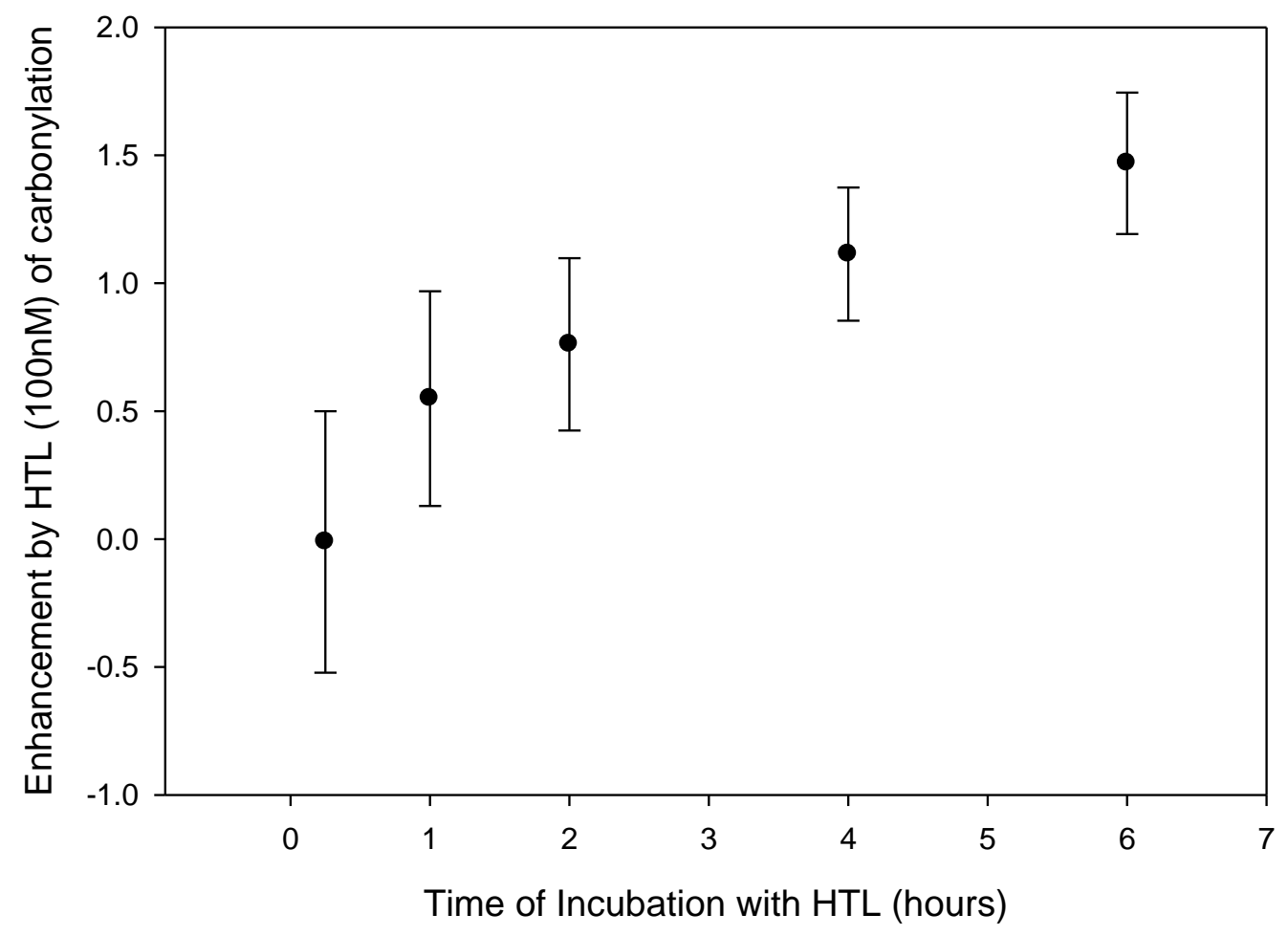

Figure 22: Enhancement of carbonylation by HTL as a function of time. Data shown is derived from Figure 21. The enhancement by $100 \mathrm{nM} \mathrm{HTL}$ of carbonyl formation is significant at 4 and 6 hours. $(P<0.1$ at 4 hours and $P<0.05$ at 6 hours.) 


\subsection{Carbonylation on RyR2 increases as a function free $\mathrm{Ca}^{2+}$, with or without}

HTL

Carbonylation increases as a function of free $\mathrm{Ca}^{2+}$ concentration with and without 100nM HTL.

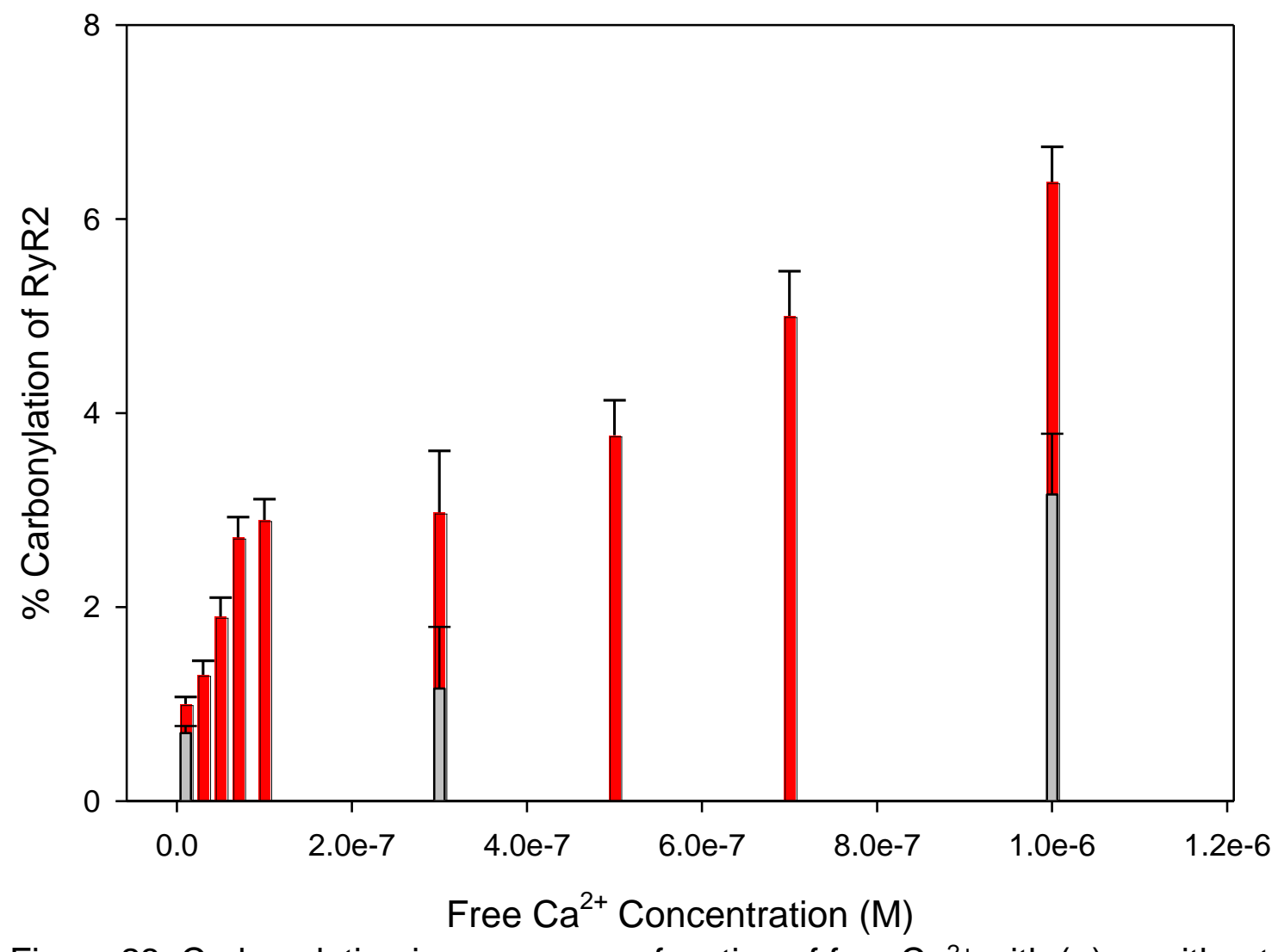

Figure 23: Carbonylation increases as a function of free $\mathrm{Ca}^{2+}$ with ( $\left.\square\right)$ or without (घ) 100nM HTL. Sheep cardiac SR vesicles were incubated with or without 100nM HTL at various free $\mathrm{Ca}^{2+}$ concentrations in ryanodine binding buffer at solution redox potential of $-210 \mathrm{mV}$ and at $37^{\circ} \mathrm{C}$. The reactions were stopped with a series of washes after 14 hours. Each value of the HTL condition contains three experiments, each from three different cardiac SR preparations and generating 1-3 PVDF membranes each that were imaged, analyzed and this value, carbonylation per ryanodine receptor, was then normalized to the control condition before being averaged and reported \pm standard error. The condition without HTL were derived from two experiments, from two different sheep cardiac SR preparations and both generating 2 PVDF membranes. 


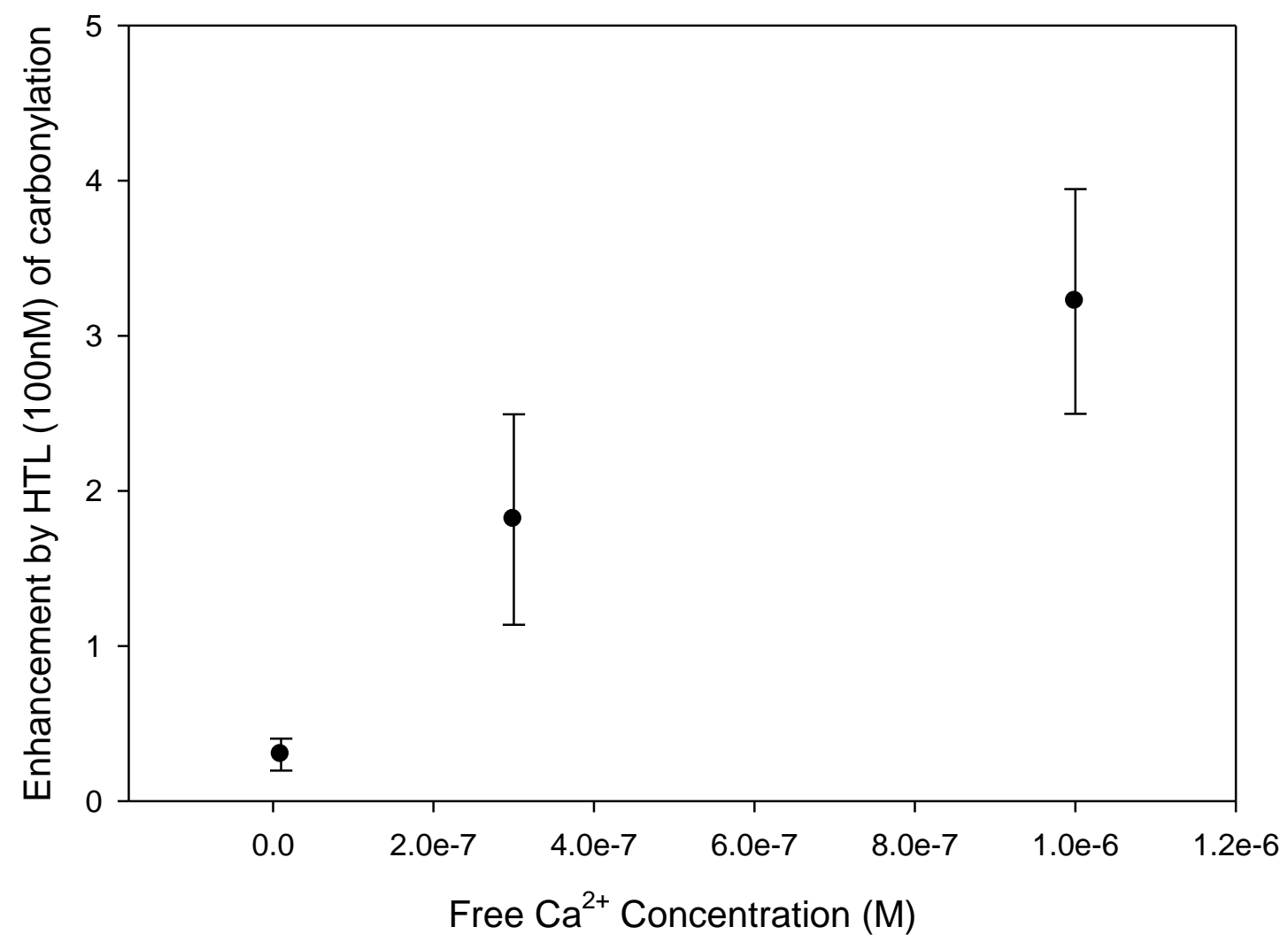

Figure 24: Enhancement of carbonylation by $\mathrm{HTL}$ as a function of $\mathrm{Ca}^{2+}$ concentration. Data shown is derived from Figure 21. The enhancement by HTL of carbonyl formation, as defined in figure 20 , is significant at $300 \mathrm{nM} \& 1 \mu \mathrm{M}$ free $\mathrm{Ca}^{2+} .(\mathrm{P}<0.05)$ 


\section{Carbonylation of other proteins as a function of free $\mathrm{Ca}^{2+}$}

The Ryanodine Receptor is not the only protein present in the SR prep that increases carbonylation as a function of free $\mathrm{Ca}^{2+}$ conditions. One such protein has a molecular mass of $205 \mathrm{kDa}$ and is shown in figure 25 . It's carbonylation as a function of free $\mathrm{Ca}^{2+}$ is quantified in figure 26 . This band did not react with an antibody to Sarcalumenin, a $\mathrm{Ca}^{2+}$ binding protein of molecular mass $170 \mathrm{kDa}$. It is most likely heavy chain myosin (molecular mass 223kDa). The $\mathrm{K}_{d} \mathrm{Ca}^{2+}$ associated with carbonyl formation of the $205 \mathrm{kDa}$ Protein is $77 \pm 8 \mathrm{nM}$.

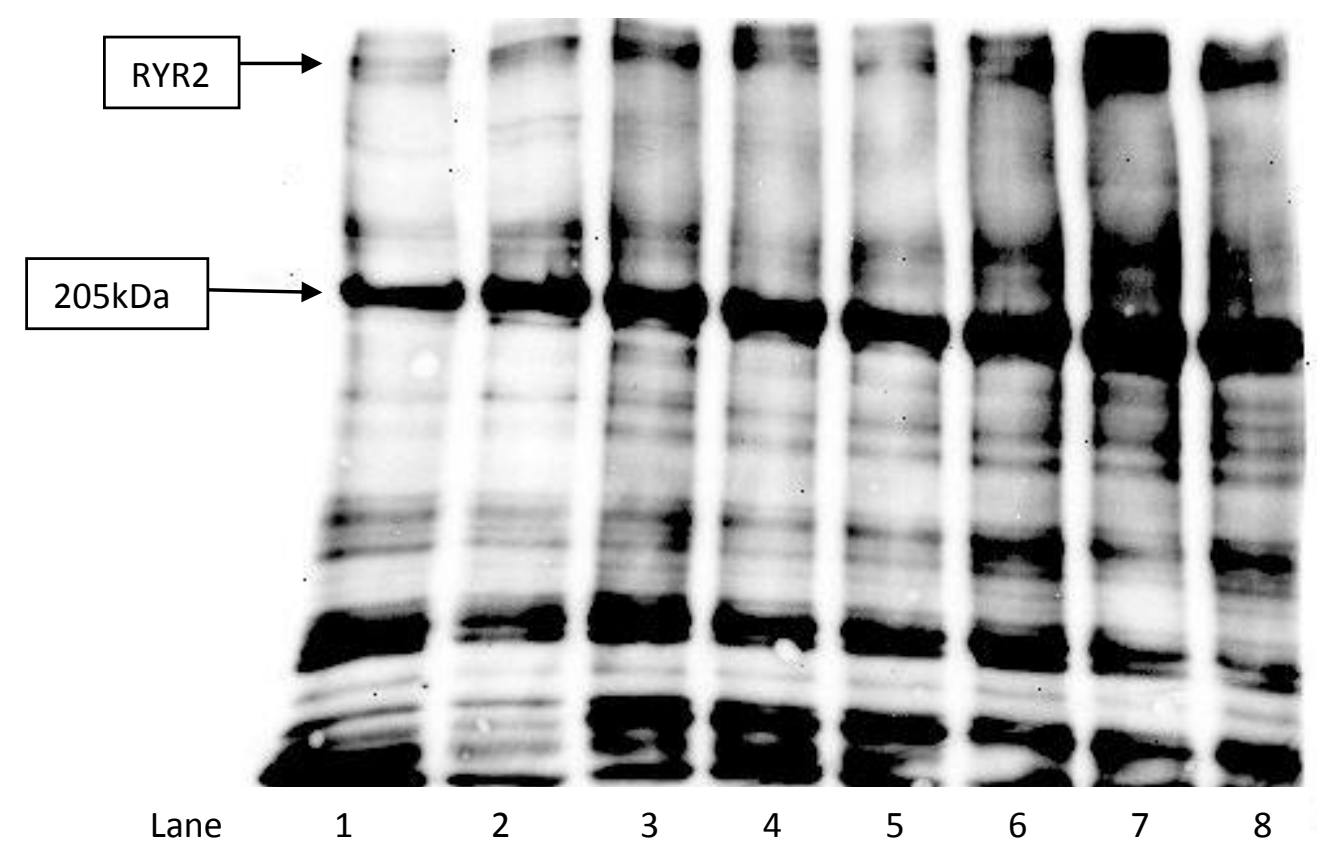

Figure 25: Western blot image of SR treated with DNPH at increasing concentrations of free $\mathrm{Ca}^{2+}$ shows increased carbonylation of multiple proteins.

Lane 1: 10nM free $\mathrm{Ca}^{2+}$ Lane 2: 30nM free $\mathrm{Ca}^{2+}$ Lane 3: 50nM free $\mathrm{Ca}^{2+}$
Lane 4: 70nM free $\mathrm{Ca}^{2+}$ Lane 5: $100 \mathrm{nM}$ free $\mathrm{Ca}^{2+}$ Lane 6: 300nM free $\mathrm{Ca}^{2+}$
Lane 7: 500nM HTL Lane 8: $7 \mu \mathrm{M} \mathrm{HTL}$ 


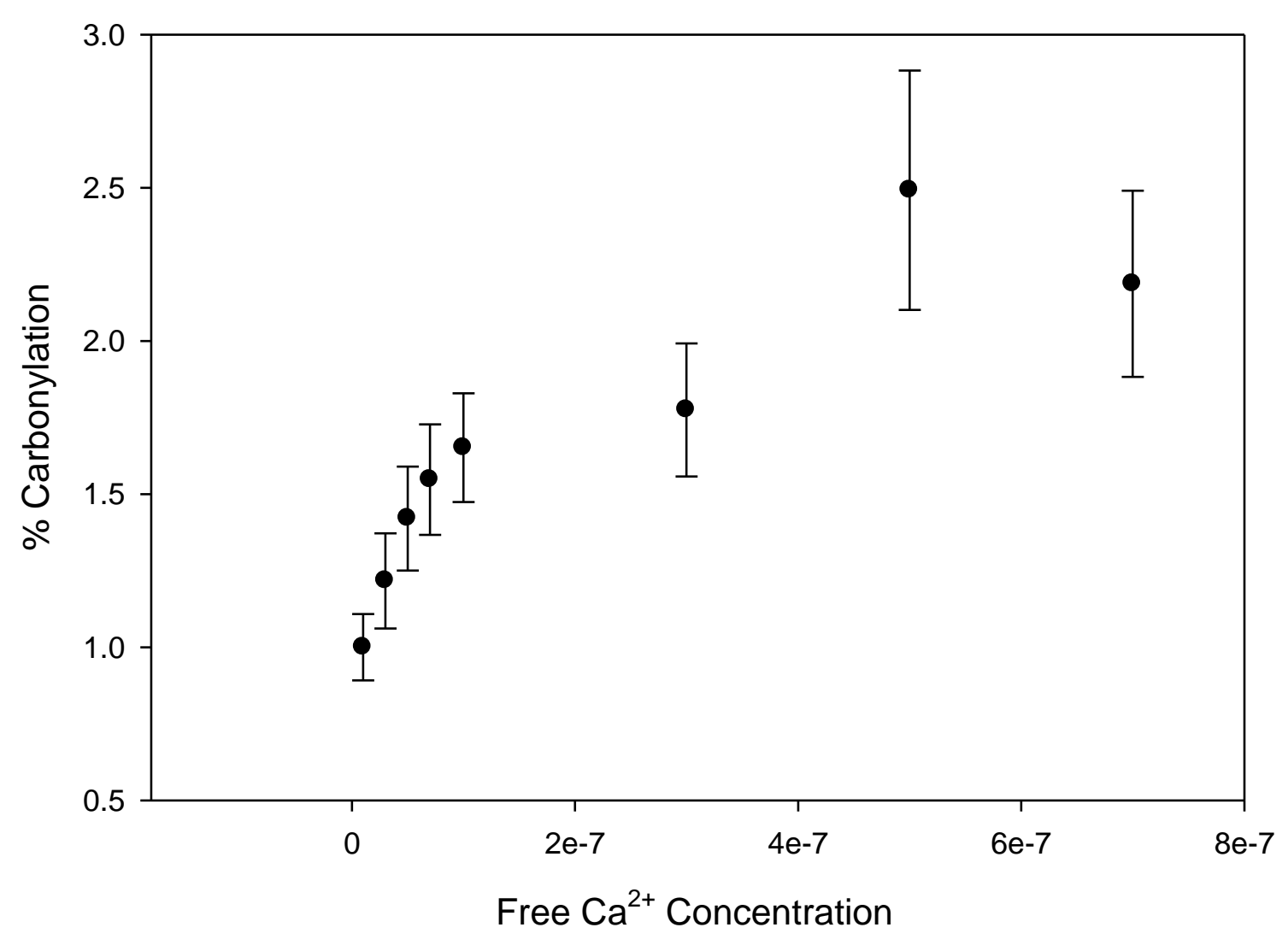

Figure 26: Carbonylation of the $205 \mathrm{kDa}$ protein as a function of free $\mathrm{Ca}^{2+}$ concentration. Sheep cardiac SR was incubated with $100 \mathrm{nM} \mathrm{HTL}$ at various free $\mathrm{Ca}^{2+}$ concentrations in ryanodine binding buffer at a solution redox potential of $-210 \mathrm{mV}$ at $37^{\circ} \mathrm{C}$ for 14 hours. The reaction was stopped with a series of washes.

Two experiment, producing 2-4 PVDF membranes that were imaged and analyzed and this value, carbonylation per ryanodine receptor, was then normalized to the control condition before being averaged and reported \pm standard error. 


\subsection{Standardization of Carbonyl formation}

Using a protein ladder that has a known amount of DNPH residues attached to bovine serum albumin, it was possible to estimate how many carbonyl groups are formed on the RyR. The oxy-blot kit claims that there are 100 fmols of DNPH residue in $2.5 \mu \mathrm{l}$ of protein ladder provided. It was found via comparison of the integrated density values of the ladder and of the RyR2 bands found on three different PVDF membranes, that $88 \mathrm{fmol}$ of carbonyls were formed above background. Since there are $15 \mu \mathrm{g}$ of SR loaded on each lane, and using the reference from a high salt $(1 \mathrm{M} \mathrm{KCl})$ binding assay (ryanodine receptor is saturated) carried out on the same $\mathrm{SR}^{50}$, there are $4.8 \mathrm{fmol}$ of RyR2 per $\mu \mathrm{g}$ of $\mathrm{SR}$, it is possible to calculate that under the following conditions; $1 \mu \mathrm{M}$ free $\mathrm{Ca}^{2+}$, $210 \mathrm{mV}$ redox potential, and $500 \mathrm{nM} \mathrm{HTL}$, there are $\sim 90 \mathrm{fmol}$ of carbonyl's are formed on $\sim 300$ fmols of RyR monomers. This works out to be approximately one in three ryanodine receptors monomers being carbonylated. The active ryanodine receptor is a tetramer, therefore each tetramer contains $\sim 1.3$ carbonyls

under these experimental conditions. At 100nM HTL, this works out to be $\sim 0.43$ carbonyl/tetramer or $1 / 2$ of the receptors are carbonylated. 


\section{Chapter 4: Conclusions \& Discussion}

In the present study, we show that physiological relevant levels of homocysteine thiolactone, decreases the amount of free calcium needed for activation of the Ryanodine Receptor which precedes muscle contraction. This change can cause defects in function characterized by heart failure, ischemic heart disease, and several forms of arrhythmias. We propose here that the RyR2's response to HTL is caused by the formation of $\mathrm{N}$-Hcy-protein complex which in turn leads to irreversible carbonyl formation.

This proposal is supported by the similarities in the following experiments. The similarity between $\mathrm{HTL}$ ability to shift $\mathrm{Ca}^{2+}$ dependent ryanodine binding, $\mathrm{IC}_{50}=90.4 \pm 15.5 \mathrm{nM}$ (figure 13) and to induce the formation of carbonyls on RyR2, $E C_{50}=108.8 \pm 20.3 \mathrm{nM}$ (figure 18) is remarkable. The case for carbonylation being the underlying mechanism of this functional change is supported by the functional studies that delved into the question of redox sensitivity (figure 15). It was observed that there is a greater change from the control condition in a reduced environment than in an oxidized one. This leads us to speculate that the RyR2's response to HTL is potentiated by an interaction with sulfhydryl groups in a reduced state. This supports our hypothesis that the $\mathrm{N} \varepsilon$-Hcy-protein complex can lead to either formation of a carbonyl or a disulfide. In a reduced environment the carbonyl formation should be favored. In contrast, measurements of carbonyl formation, showed no preference for the redox state of the receptor (figure 19 \& figure 20). 
An alternate hypotheses that we have disproven is that the formation of HTL adduct(s) with the large excess of GSH present in our experiments and in the cell environment, would form "downstream" products that serve as RyR modulators (figure 14). Since these studies are done with 700nM HTL or less, with an excess of $2 \mathrm{mM} \mathrm{GSH}$, an argument could be made for the presence of hyperactive lysine or a preferential condition that pushes the HTL to react with the RyR2 and not with the other free amine groups available. Since physiological conditions include a large excess of glutathione and other free amines, and only a small number of carbonyls are formed on RyR2, there appears to be something special about the environment that favors carbonyl formation with these hyper reactive lysines.

The largest discrepancy we have found between the functional change and the formation of carbonyls is when looking at the time scale over which these changes happen. Carbonyl formation peaks at 4 hours (figure 21) while the functional change is still increasing at 6 hours (figure $16 \&$ table 4 ).

The concentration of free $\mathrm{Ca}^{2+}$ on carbonyl formation had a significant effect (figure 23). This may be due to $\mathrm{Ca}^{2+}$ acting as a catalyst, or more likely it is caused by a $\mathrm{Ca}^{2+}$ dependent conformational change in RyR2 which exposes site(s) at which carbonyls form. This question should be explored further. Further investigation will also have to be done with respects to the number of receptors being modified. With approximately one in three ryanodine receptor monomers being modified in a 14 hour time scale the question is raised whether or not a 
modified ryanodine receptor will exist for enough time to impact heart health in the body. The ryanodine receptor is usually turned over every 9-12 days ${ }^{51}$, however this could happen faster if proteases in the body recognize it functioning improperly. Is HTL reacting with so few sites on the RyR2 or is the formation carbonyl groups just an intermediary step and downstream products have not yet been identified? On a more basic, mechanistic level, future experiments could be done into how carbonyl formation is altered in the presence of other activators and inhibitors. These questions can be answered using the protocols outlined here with the antibodies to DNPH.

Marks and colleagues ${ }^{52}$ have shown that RyR 1 is carbonylated in the aging mouse model and Bidase ${ }^{33}$ has shown that RyR2 is carbonylated in the diabetic rat model. This is the first time that it has been shown that increasing HTL concentrations results in the formation of carbonyls on RyR2 and that this appears to result in a $\mathrm{Ca}^{2+}$ dependent shift in ryanodine binding. This is a new molecular mechanism linking elevated levels of Homocysteine, improper $\mathrm{Ca}^{2+}$ handling and heart failure. 


\section{References}

${ }^{1}$ Dulhunty, A.F., Junankar, P.R., Eager, K.R., Ahern, G.P., and Laver, D.R. "Ion channels in the sarcoplasmic reticulum of striated muscle." Acta Physiol. Scand. 156:375-385 (1996).

2 Voet, D., Voet, J.G. Biochemistry. John Wiley \& Sons, Inc. 1990.

3 Heiny, J.A. "Excitation-Contraction Coupling in Skeletal Muscle." Cell Physiology Source Book: 805-816 (1998).

${ }^{4}$ Bers, D.M. "Cardiac excitation-contraction coupling." Nature 415: 198-205 (2002)

${ }^{5}$ McComas, T. "Skeletal muscle: form and function." Human Kinetics, Champaign, IL, 1996

${ }^{6}$ Spiecker, I., Luttgau, R. "The effects of calcium deprivation upon mechanical and electrophysiological parameters in skeletal muscle fibers of the frog." J. Physiol. 296: 411-429 (1979)

${ }^{7}$ Fabiato, A. "Calcium-induced release of calcium from the cardiac sarcoplasmic reticulum." Am. J. Physiol. 245: C1-C14 (1983).

${ }^{8}$ Venetucci, L.A., Trafford, A.W., O’Neill, S.C., Eisner, D.A. "The sarcoplasmic reticulum and arrhythmogenic calcium release." Cardiovasc Res 77:285-292 (2008).

${ }^{9}$ Pogwizd, S.M., Bers, D.M. "Cellular basis of triggered arrhythmias in heart failure." Trends Cardiovasc. Med. 14:61-66 (2004).

10 Takeshima, H., Nishimura, S., Matsumoto, T., Ishida, H., Kangawa, K., Minamino, I. "Primary structure and expression from complementary DNA of skeletal muscle ryanodine receptor." Nature 339:439-445 (1989).

${ }^{11}$ Imagawa, T., Smith, J., Coronado, R. and Campbell, K. "Purified ryanodine receptor from muscle sarcoplasmic reticulum is the $\mathrm{Ca}^{2+}$ permeable pore of the calcium release channel." J. Biol. Chem. 262:16636-16643 (1987).

12 Otsu, K., H.F. Willard, V. K. Khanna, F. Zorzato, N. M. Green and D. H. MacLennan. "Molecular cloning of cDNA encoding the $\mathrm{Ca}^{2+}$ release channel (ryanodine receptor) of rabbit cardiac muscle sarcoplasmic reticulum." Journal of biological chemistry 265 (23):13472-13483

${ }^{13}$ Orlova, E.V. "Two structural configurations of the skeletal muscle calcium release channel." Nature struct. Biol. 3:547-552 (1996).

${ }^{14}$ Meissner, G. "Ryanodine receptor/ $\mathrm{Ca}^{2+}$ release channels and their regulation by endogenous effectors." Annual review of physiology 56:485-508 (1994).

${ }^{15}$ Smith, J.S., Coronado, R., and Meissner, G. "Single Channel measurements of the calcium release channel from skeletal muscle sarcoplasmic reticulum:

Activation by $\mathrm{Ca}^{2+}$ and ATP and modulation by $\mathrm{Mg}^{2+}$." J. Gen. Physiol 88:573-588 (1986).

${ }^{16}$ Stephen, R., Holmberg, M., and Williams, A. "Patterns of interaction between anthraquinone drugs and the calcium release channel from cardiac sarcoplasmic reticulum." Circulation Research 67:272-283 (1990). 
${ }^{17}$ Abramson. J.J. and Salama, G. "Critical sulfhydryls regulate calcium release from sarcoplasmic reticulum." J. Bioenergetics and Biomembranes 21(2):283-294 (1989).

${ }^{18}$ Euikyung, K., Shri, N., Giri, P. and Pessah, I. "Iron (II) is a modulator of ryanodine sensitive calcium channels of cardiac muscle sarcoplasmic reticulum." Toxicology and Applied Pharmacology, 130:57-66 (1995).

${ }^{19}$ Xia, R., Strangler, T., Abramson, J.J. "Skeletal Muscle Ryanodine Receptor is a redox sensor with a well defined redox potential that is sensitive to channel modulators." J. Biol. Chem 275:36556-36561 (2000).

${ }^{20}$ Abramson, J.J., Salama, G. "Sulfhydryl oxidation and Ca2+ release from sarcoplasmic reticulum." Mol. Cell. Biochem. 82:81-84 (1988).

${ }^{21}$ Evelo, C.T.A., Palmen, N.G., Arthur, Y. and Janssen, G.M.E. "Changes in blood glutathione concentrations, and in erythrocyte glutathione reductase and glutathione S-transferase activity after running training and after participation in contests." Eur. J. Appl. Physiol. 64:354-358 (1992).

$22 \mathrm{Ji}$, L.L., Fu, R.G., and Mitchell, E. W. "Glutathione and antioxidant enzymes in skeletal muscle: effects of fiber type and exercise intensity." J. Apply. Physiol. 73:185-1859 (1992).

${ }^{23}$ Jalilian, C., Gallant, E.M., Board, P.G., and Dulhunty, A.F. "Redox potential and the response of cardiac ryanodine receptors to CLIC-2, a member of the glutathione S-transferase structural family." Antioxid Redox Signal 10:1675-86 (2008).

${ }^{24}$ Hwang, C., Sinskey, A.J., and Lodish, H.F. "Oxidized redoxs rates of glutathione in the endoplasmic reticulum." Science 257:1496-1502 (1992). ${ }^{25}$ Glushchenko, A.V., Jacobesen, D.W. "Molecular targeting of proteins by Lhomocystine: Mechanistic implications for vascular disease." Antioxid. Redox Signaling 9:1183-1898 (2007).

${ }^{26}$ Sibrian-Vazquez, M., Escobedo, J.O., Lim, S., Samoei, G.K., Strongin, R.M. "Homoccystamides promote free-radical and oxidative damage to proteins." PNAS USA 107:551-554 (2010).

${ }_{27}$ McCully, K.S. "Vascular pathology of hyperhomocysteinemia: Implications for the development of arteriosclerosis." Am. J.Path. 56:111-128 (1969).

28 Joseph, J., Handy, D., Loscalzo, L. "Quo Vadis: Whither Homocysteine Research?" Cardiovasc Toxicol. 9(2): 53-63 (2009)

${ }^{29}$ Carnel, R., Jacobsen, D.W. Homocysteine in health and disease. Cambridge University Press: Cambridge, U.K. (2001).

30 Jakubowski, H. "Biomedicine and disease: review molecular basis of homocysteine toxicity in humans." CMLS, Cell. Mol. Life Sci. 61:470-487 (2004).

${ }^{31}$ Jakubowski, H. "Metabolism of homocysteine thiolactone in human cell cultures: possible mechanism for pathological consequences of elevated homocysteine levels." J. Biol. Chem. 272:1935-1942.

32 Jakubowski, $\mathrm{H}$. "Proofreading in vivo: editing of Homocysteine by methionyltRNA synthetase in the yeast Saccharomyces cerevisiae." EMBO J. 10:593-598 (1991). 
${ }^{33}$ Rauk, A., Armstrong, D.A., Fairlie, D.P. "Is oxidative damage by p-Amyloid and Prion Peptides mediated by hydrogen atom transfer from Glycine $\alpha$-Carbon to Methionine Sulfur within p-Sheets?" J. Am. Chem. Soc. 122:9761 (2000). ${ }^{34}$ Andersson DC, Betzenhauser MJ, Reiken S, Meli AC, Umanskaya A, Xie W, Shiomi T, Zalk R, Lacampagne A, Marks AR. "Ryanodine receptor oxidation causes intracellular calcium leak and muscle weakness in aging." Cell Metab.14(2):196-207 (2011)

${ }^{35}$ Shao, CH., Tian, C., Ouyang, S., Moore, C.J., Alomar, F., Nemet, I., D'Souza, A., Nagai, R., Kutty, S., Rozanski, G.J., Ramanadham, S., Singh, J., Bidasee, K.R. "Carbonylation Induces Heterogeneity in Cardiac Ryanodine Receptor Function in Diabetes Mellitus" Mol. Pharm. 82:383-399 (2012)

${ }^{36}$ Brownlee M, Cerami A, Vlassara H. "Advanced glycosylation end products in tissue and the biochemical basis of diabetic complications." N Engl J Med 318:1315-1321.

${ }^{37}$ Shao, C., Capek, H., Patel, K., Wang, M., Tang, K., DeSouza, C., Nagai, R., Mayhan, W., Periasamy, M., Bidasee, K. "Carbonylation contributes to SERCA2a activity loss and diastolic dystunction in a rat model of type 1 diabetes." Diabetes 60:947-959 (2011).

${ }^{38}$ Iberg N, Flückiger R. "Nonenzymatic glycosylation of albumin in vivo. Identification of multiple glycosylated sites." J Biol Chem. 261(29):13542-5. (1989)

${ }^{39}$ Bidasee, K.R., Nallani, K., Yu, Y., Cocklin, R.R., Zhang, Y.,Wang, W., Dincer, U.D., Besch, H.R. "Chronic Diabetes Increases Advanced Glycation End Products on Cardiac Ryanodine Receptors/Calcium Release Channel. Diabetes 52:1825-1836 (2003)

${ }^{40}$ Meissner, G., Henderson, J.S. "Rapid calcium release from cardiac sarcoplasmic reticulum vesicles is dependent on $\mathrm{Ca}^{2+}$ and is modulated by $\mathrm{Mg}^{2+}$, adenine nucleotide, and calmodulin.” J. Biol. Chem. 262:3065-3073 (1987).

${ }^{41}$ Kalckar, M. "Differential spectrophotometry of purine compounds by means of specific enzymes." J. Biol. Chem. 167:461-475 (1947).

${ }^{42}$ Lowry, Oliver $\mathrm{H}_{\text {., }}$ et al. "Protein measurement with the Folin phenol reagent." J biol Chem 193.1: 265-275. (1951)

${ }^{43}$ Moody, GJ., Oke, RB., Thomas, JDR. "A calcium-sensitive electrode based on a liquid ion exchanger in a poly (vinyl chloride) matrix." Analysis 95: 910-918 (1970)

${ }^{44}$ Baudet, S., Hove-Madsen, L., Bers. DM. "How to Make and Use CalciumSpecific Mini- and Microelectrodes" Methods in Cell Biology Volume 40:93-113 (1994)

${ }^{45}$ Pessah, I.N., Stambuk, R.A., Casida, J.E. "Ca ${ }^{2+}$ activated ryanodine binding: mechanisms of sensitivity and intensity modulation by $\mathrm{Mg}^{2+}$, caffeine, and adenine nucleotides." Mol. Pharmacol. 31:232-238 (1987).

${ }^{46} \mathrm{pH}$ Dependent Redox Couple: An Illustration of the Nernst Equation 
Walczak, M.W., Dryer, D.A., Jacobson, D.D., Foss, M.G., Flynn, N.T. "pH Dependent Redox Couple: An Illustration of the Nernst Equation" Journal of Chemical Education 74 (10): 1195-1197

47 Wang, P., Powell, S.R. "Decreased sensitivity associated with an altered formulation of a commercially available kit for detection of protein carbonyls." Free Radic Biol Med. 49(2):119-121

48 Towbin H, Staehelin T, Gordon J. "Electrophoretic transfer of proteins from polyacrylamide gels to nitrocellulose sheets: procedure and some applications." Proc Natl Acad Sci 76(9):4350-4. (1979)

${ }^{49}$ Sadeqzadeh, E., C. E. de Bock, X.D. Zhang, K.L. Shipman, N.M. Scott, C. Song, P. Hersey, A.W. Boyd, G. F. Burns, R.F. Thorne. "Dual processing of FAT1 cadherin protein by human melanoma cells generate distinct protein products." Journal of Biological Chemistry 286 (32):28181-28191

${ }^{50}$ Franzini-Armstrong, C., and Protasi, "Ryanodine receptors of striated muscles: a complex channel capable of multiple interactions" F. Physiol. Rev. 77, 699-729 (1997)

${ }^{51}$ Ferrington DA, Krainev AG, Bigelow DJ. "Altered turnover of calcium regulatory proteins of the sarcoplasmice reticulum in aged skeletal muscle." J Biol Chem 273:5885-5891 (1998)

${ }^{52}$ Andersson DC, Betzenhauser MJ, Reiken S, Meli AC, Umanskaya A, Xie W, Shiomi T, Zalk R, Lacampagne A, Marks AR. "Ryanodine receptor oxidation causes intracellular calcium leak and muscle weakness in aging." Cell Metab.14(2):196-207 (2011) 